$\widehat{\mathcal{G}}_{\text {http://dx.doi.org/10.3765/sp.9.3 }}^{\text {Semantics \& Pragmatics Volume 9, Article 3: 1-54, } 2016}$

\title{
Focus fronting, unexpectedness, and evaluative implicatures*
}

\author{
Valentina Bianchi \\ University of Siena
}

\author{
Giuliano Bocci \\ University of Geneva
}

\author{
Silvio Cruschina \\ University of Vienna
}

Submitted 2013-01-07 / First decision 2013-03-29 / Revision received 2014-03-10 / Second decision 2014-05-26 / Revision received 2014-08-01 / Third decision 201412-19 / Revision received 2015-03-26 / Accepted 2015-04-29 / Final version received 2015-04-29 / Published 2016-11-30

\begin{abstract}
This paper discusses the fronting of a focal constituent to a clauseinitial position which, in various languages, is associated with an import of unexpectedness. We provide prosodic and syntactic evidence from Italian showing that this phenomenon has distinctive grammatical properties with respect to other instances of "focus fronting". We argue that the fronted constituent bears narrow focus, and that the unexpectedness import conveys that the asserted proposition is less likely than one or more distinct focus alternatives (see Grosz 2011). We characterize this import as a conventional implicature, and we argue that likelihood is interpreted with respect to an informative modal base which is shared by the conversational community (the context set). We show that the unexpectedness import expressed by a speaker can be accepted or rejected by the other discourse participants: thus, it qualifies as an evaluative commitment of the speaker and, when accepted by the interlocutors, it can give rise to a shared evaluation.
\end{abstract}

Keywords: focus fronting, unexpectedness, context, ordering source, evaluation

* We would like to thank the S\&P anonymous reviewers and editor Kai von Fintel who, with their comments, suggestions and encouragement, helped us greatly to improve this paper during the stages of the reviewing process. We are also very grateful to Ur Shlonsky and the audience of the Workshop "Syntactic cartography: Where do we go from here?" (Geneva, June 2012), to the audience of "Going Romance 2013" (Amsterdam, December 2013), and to Adriana Belletti and Luigi Rizzi for valuable remarks on the occasion of a talk in Siena (January 2014). We are finally thankful to Anna Kocher and Nina Haslinger for their help with checking over the final version of this paper. Any remaining errors are our own responsibility.

Giuliano Bocci's work was supported by the ERC Advanced Grant 340297 SynCart.

(C)2016 Bianchi \& Bocci \& Cruschina

This is an open-access article distributed under the terms of a Creative Commons Attribution License (http://creativecommons.org/licenses/by/3.o/). 


\section{Introduction}

In various languages we observe the fronting of a focal constituent, bearing the main prosodic prominence, to a left-peripheral position. This structure may convey different interpretive effects in specific contexts. One interesting instance of such "focus fronting" conveys that the proffered information is unexpected or surprising (see, a.o., Zimmermann 2007, Hartmann \& Zimmermann 2007 on Hausa; Abeillé, Godard \& Sabio 2008 on the French construction II; Frey 2010 on German; Cruschina 2012 on Sicilian dialects). Some illustrative examples are reported in (1)-(4). ${ }^{1}$

(1) Tu sais ce qui est arrivé? Le candidat du patron, ils you know what is happened the candidate of-the boss they ont refusé! have.3PL refused

'You know what happened? They refused the boss's candidate!' (French; Abeillé, Godard \& Sabio 2008, (19a))

(2) A: Chi successi? what happen.PAST.3SG

B: A machina m' arrubbaru! the car me.cL stole.3PL

'- What happened? - My car was stolen!'

(Sicilian; Cruschina 2012: 71, (92))

(3) Sai come lo chiamava il suo amico? "Novellino"

know.2SG how him.CL called.IPF.3SG the his friend greenhorn lo chiamava.

him.CL called.IPF.3SG

'Do you know how his friend called him? He called him greenhorn.'

(Italian; from S. Veronesi, No man's land, Milan 2003)

1 Throughout the paper the constituent that bears main prosodic prominence is marked in italics. 
Fronting and unexpectedness

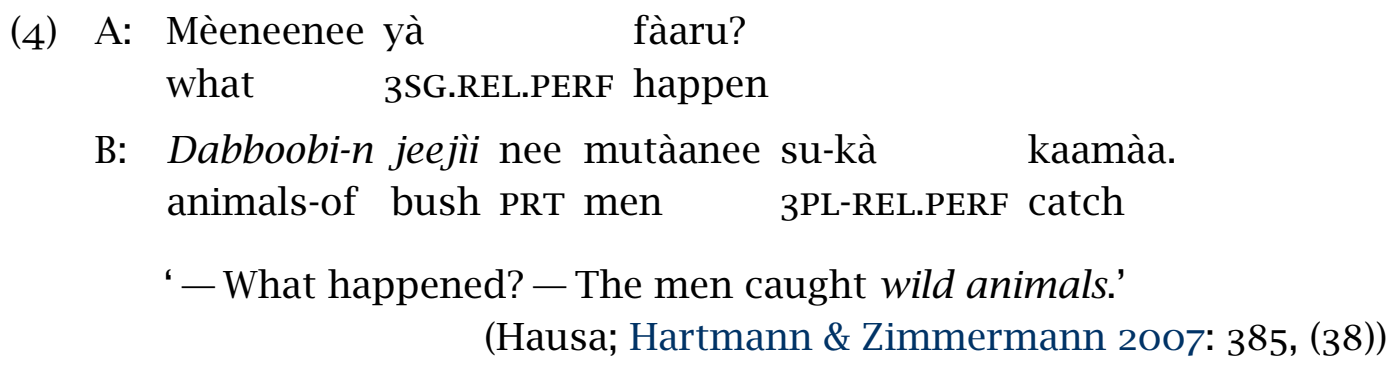

In this paper we provide an empirical characterization of this structure in Italian and a formal analysis elucidating the role of focus. In Section 2 we show that this structure is characterized by specific prosodic and syntactic properties, differing from another instance of focus fronting that occurs in corrective replies to an assertion: this implies that the unexpectedness import is grammatically encoded, rather than being one out of many pragmatically possible uses of a general "focus fronting" structure. In Sections 3 and 4 we argue that this import qualifies as a conventional implicature (CI) by Potts's (2007b) criteria; building on Frey 2010 and Grosz 2011, we characterize it in terms of the comparative likelihood of alternative propositions: there are one or more focus alternatives which are more likely than the proposition expressed by the clause. We then provide a compositional analysis in Potts's framework for CIs.

On Potts's characterization, conventional implicatures are typically anchored to the speaker. In Section 5 we argue instead that the unexpectedness import in our structure is not exclusively anchored to the speaker, but rather, it is interpreted with respect to a modal base which is shared by the conversational participants (i.e., the context set); moreover, the ordering source can be anchored to the speaker, to the hearer, or to both. We show that, crucially, the unexpectedness import can be accepted or rejected by the other discourse participants, depending on the ordering source that is adopted: in this respect, it differs from Potts's expressive meaning (although both are separate from the at-issue meaning).

In Section 6 we relate our analysis to the general issue of "mirativity". In Section 7 we discuss an apparent paradox concerning the coexistence of narrow focus on the fronted constituent with broad focus required by question-answer congruence in sentences like (1), (2) or (4) above. Finally, Section 8 provides a synthesis of our proposals and some concluding remarks.

One proviso is in order right at the beginning. Following Cruschina (2012: 117-118), we will dub the structure exemplified in (1)-(4) mirative 
fronting (MF). This label is inspired by DeLancey's (1997) definition of the grammatical category of mirativity, whereby the speaker expresses that the information she is asserting has been very recently acquired and is not yet integrated in her system of beliefs (see Aikhenvald 2012 for general discussion). By using the term "mirative", our aim is to contribute to the empirical call for "further in-depth studies of how languages mark new information and surprise in their grammars" (Aikhenvald 2004: 215). However, there is no consensus as to whether mirativity must be treated as a separate category (Aikhenvald 2004, Torres Bustamante 2012, 2013, a.o.) or as an overtone or extension of evidential markers (Lazard 1999, 2001, Rett \& Murray 2013, a.o.). The issue is particularly difficult to tackle in light of the wealth of different phenomena that manifest an unexpectedness import across languages: most notably exclamative clauses (see, a.o., Zanuttini \& Portner 2003, Rett 2011, Peterson 2010, 2012, Giurgea 2014), exclamations (Rett 2011), European Portuguese "evaluative fronting" (Ambar 1999), (some uses of) German $\bar{A}$ fronting (Frey 2010), unembedded dass-clauses in German (Grosz 2011), the mirative use of the imperfect in Spanish (Torres Bustamante 2012, 2013), and mirative evidentials (Rett \& Murray 2013).

Many questions concerning the semantics of mirativity within a wide crosslinguistic perspective are therefore still open. In the absence of a generally accepted semantic account and of defining formal criteria, we will not deal with the issue of the connection between mirativity and evidentiality, nor will we examine the many potential links between our proposal and other treatments of mirativity in different grammatical systems or strategies. We will only provide a concise comparison with some proposals in the recent literature (see notes 8, 12, 19, 25, 26 and Section 6). Similarly, we postpone to future research the task of a detailed crosslinguistic comparison: the limited aim of this paper is to analyse Italian focus fronting as a grammatical strategy conveying a mirative meaning, and to provide a detailed characterization of its prosodic, syntactic and interpretive properties. This, we believe, is a necessary starting point for a rigorous comparative work.

\section{Empirical characterization of the phenomenon}

The first step in our argument is to provide a precise empirical characterization of mirative fronting. We will focus here on Italian.

To begin with, it is important to stress that in Italian focus fronting is not univocally associated with a mirative import of unexpectedness, as 
Fronting and unexpectedness

exemplified in (1)-(4) above; it can also be associated with a corrective import, as in $\left(5^{B}\right)$, whereby speaker $\mathrm{B}$ rejects A's assertion and asserts a distinct proposition (see Bianchi \& Bocci 2012):

(5) A: Gianni ha regalato una collana a Maria. John has given a necklace to Mary

B: Un anello le ha regalato.

a ring her.CL has given

'A: John gave Mary a necklace. B: No, he gave her a ring.'

The corrective import emerges in a reply immediately following an assertion, which is the target of the correction (here, $(5 \mathrm{~A})$ ). On the other hand, it is unavailable in polar questions: for example, $(6 \mathrm{~B})$ cannot be used to correct the propositional content of the question in (6A).

(6) A: La domanda cruciale è: ha davvero insultato il suo collega? the question crucial is has really insulted the his colleague

B: \#Il direttore ha insultato?

the director has insulted

Intended:

A: The crucial question is: did he really insult his colleague?

B: (No, the crucial question is:) Did he insult the director?

MF has a wider distribution: as we saw in (1)-(4), it can be hosted in answers to questions or in all-new sentences; furthermore, it is also possible in polar questions like (7).

(7) Ma domani al mare andate?

but tomorrow to-the seaside go.2.PL

'Are you going to the seaside tomorrow?'

However, the different distribution across various contexts does not tell us per se whether these two instances of fronting are grammatically distinct phenomena or just two potential uses of the same fronting structure which happen to be felicitous in different contexts. It is therefore necessary to compare their prosodic and syntactic properties. 
Bianchi \& Bocci \& Cruschina

\subsection{Prosodic evidence}

We designed a prosodic experiment on Italian with two aims. The first was to make sure that both in corrective and in mirative instances of fronting, the fronted constituent qualifies as a narrow focus from a prosodic point of view, that is, it bears main prominence while the rest of the clause is uttered as prosodically subordinate to it. The second aim was to ascertain whether the fronted constituent has the same or a distinct prosodic profile in the two types of context: should a systematically different profile be observed, this would indicate that the corrective import and the mirative import are grammatically distinct.

The experimental items were six pairs of sentences in which a fronting structure was presented in two types of context (see the Appendix for more details on the methodology, an in-depth discussion of the results, and for the list of the experimental items):

(a) In mirative contexts, the target sentence is an assertion and the surrounding context elicits the mirative import. See (8).

(8) [Anna and Beatrice talk about Lea, Gianni and their recent wedding.]

$\mathrm{A}$ : $\mathrm{E}$ io che pensavo che non avessero nemmeno and I that think.PAST.1SG that not have.SBJV.3PL even un soldo! Indovina un po'?! Alle Maldive sono andati in a cent guess a little to-the Maldives are.3PL gone in viaggio di nozze! journey of wedding

'I thought they were penniless! Guess what?! They went to the Maldives on honeymoon!'

(b) In corrective contexts, the target sentence is a reply where the fronted constituent corrects part of an immediately preceding assertion (contrast across utterances). The target sentence is followed by a negative coda which explicitly denies the corrected alternative. See (9). 
Fronting and unexpectedness

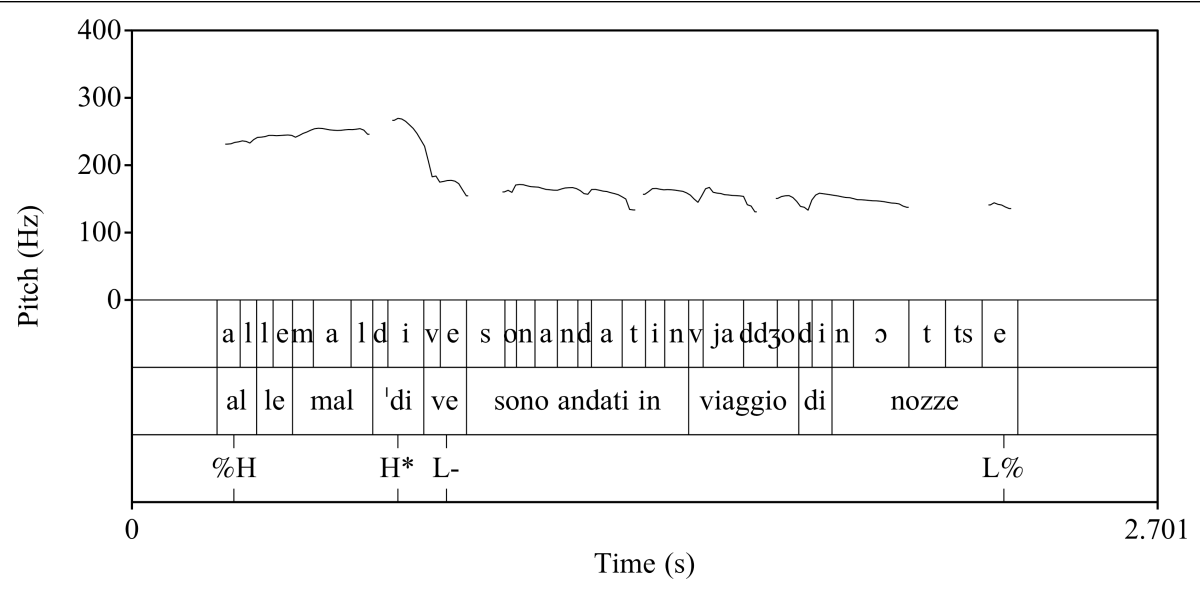

Figure 1 Pitch contour of an utterance produced after the stimulus (8) in the mirative condition: Alle Maldive sono andati in viaggio di nozze!

(9) [Anna and Beatrice talk about Lea, Gianni and their recent wedding.]

A: Se ho capito bene, sono andati alle isole if have.1SG understood well are.3PL gone to-the islands Vergini.

Virgin

$\mathrm{B}$ : No, ti sbagli! Alle Maldive sono andati in no, you.CL be-wrong.2SG to-the Maldives are.3PL gone in viaggio di nozze! Non alle isole Vergini! journey of wedding not to-the islands Virgin

'A: If I've understood correctly, they went to the Virgin Islands.

B: No, you are wrong! They went to the Maldives on honeymoon! Not to the Virgin Islands!'

The results show that in both conditions, the fronted constituent associates with a nuclear pitch accent, while the rest of the clause is always realized with a flat and low f0 contour and is prosodically subordinate to the fronted constituent. This finding confirms that the fronted constituent qualifies as a narrow focus in both contexts. However, the two conditions crucially contrast with respect to the intonational patterns associated with the focused constituent. Consider the pitch contours in Figure 1 and Figure 2. 


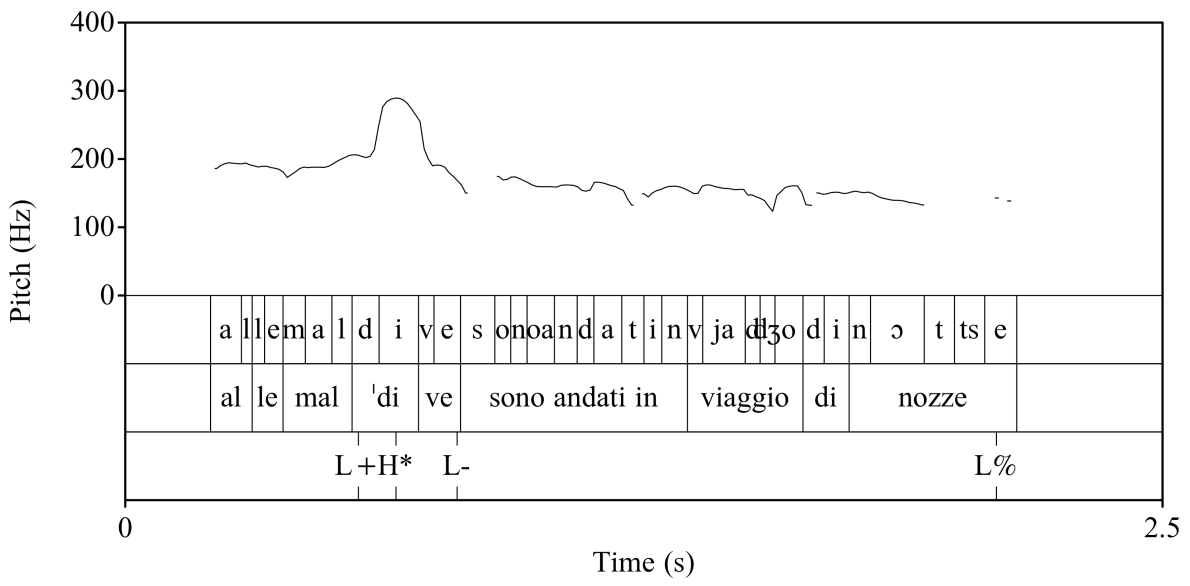

Figure 2 Pitch contour of an utterance produced after the stimulus (9) in the corrective condition: Alle Maldive sono andati in viaggio di nozze!

In the mirative condition, the fronted constituent is typically realized with a high plateau profile that starts from the very beginning of the focused constituent and stays steadily high, or slightly rises, to reach a high target within the last stressed syllable of the constituent. After the peak, the contour falls toward a low target on the final syllable of the focused constituent (see Figure 1). A minor prosodic boundary was perceivable at the end of the focused constituent.

The phonetic analysis of the pitch contour led us to conclude that the left edge of the focus constituent in the mirative condition associates with a \%H boundary tone. As for the pitch accent, depending on the early or late alignment of the high target within the stressed syllable, most part of the stressed syllable was realized either with a fall (when the high target was aligned with the vowel onset) or with a sustained high plateau (when the high target was aligned late in the rhyme). We accordingly labelled the pitch accent associated with the stressed syllable as $\mathrm{H}^{*}$ (in case of early alignment), or as $\mathrm{H}+\mathrm{L}^{*}$ (in case of late alignment). According to our analysis, the high plateau characterizing the fronted constituent in the mirative condition results from the interpolation of the initial high boundary \% $\mathrm{H}$ tone with the high tone specified for the pitch accent (either $\mathrm{H}^{*}$ or $\mathrm{H}+\mathrm{L}^{*}$ ). The low target at the end of fronted constituent was analysed as a L- phrase accent associated with the right edge of the focused constituent. 
Fronting and unexpectedness

In the corrective condition, the fronted constituent is not realized with a high plateau, and the pitch contour does not start high at the beginning of the fronted constituent. In this condition, the rightmost word of the fronted constituent is typically realized with a rise-fall pitch contour (see Figure 2). From a clear low target aligned with the onset of the stressed syllable, the pitch steeply rises to reach a peak aligned within the rhyme of the stressed syllable. After the peak, the contour falls towards a second low target, aligned with the final syllable of the constituent. In line with previous results (see Bocci 2013 and references cited therein), we interpret this rise-fall contour in terms of a $\mathrm{L}+\mathrm{H}^{*}$ pitch accent followed by a $\mathrm{L}$ - phrase accent that marks the right-hand boundary of the fronted constituent.

According to our analysis (see the Appendix), the intonational pattern associated with the fronted constituent in the mirative condition corresponds to $\% \mathrm{H} \mathrm{H}+\mathrm{L}^{*} \mathrm{~L}$ - or $\% \mathrm{H} \mathrm{H}^{*} \mathrm{~L}-$, while the tune of the fronted constituent in the corrective condition is $\mathrm{L}+\mathrm{H}^{*} \mathrm{~L}-$. The two conditions hence contrast in two respects. First, the left boundary of the fronted constituent associates with a high boundary tone in the mirative condition, while it is low (or unspecified) in the corrective condition. Second, the rightmost stressed syllable of the fronted constituent associates with different nuclear pitch accents in the two conditions. In the corrective one, we observed the pitch accent $\mathrm{L}+\mathrm{H}^{*}$, characterized by a steep rise from a clear low target aligned on the syllabic onset. In the mirative one, we observed the nuclear pitch accents $\mathrm{H}^{*}$ and $\mathrm{H}+\mathrm{L}^{*}$, in which such a steep rise was totally absent.

These findings show that the corrective and the mirative import associate with different intonational properties. We therefore conclude that MF is grammatically distinct from focus fronting carrying a corrective import. In the following section we summarize some syntactic evidence, drawn from Cruschina 2012, which also supports this conclusion.

\subsection{Further evidence from syntax}

Cruschina (2012), in analysing Sicilian and standard Italian, identified two syntactic properties which discriminate fronting in mirative vs. corrective contexts; we will here provide examples from Italian.

First, in the mirative case the fronted constituent cannot be separated from the finite verb by an intervening constituent, as shown in (10b). On the contrary, in corrective contexts adjacency is not required, as shown in (11B). 
(10) a. Non ci posso credere! Due bottiglie ci siamo bevuti! Not CL.LOC can believe two bottles CL be.PRES.1PL drunk.PL

'I can't believe it! We drank two bottles!'

b. ??/*Non ci posso credere! Due bottiglie, al pub, ci not CL.LOC can believe two bottles at-the pub CL siamo bevuti! be.1PL drunk.PL

'I can't believe it! We drank two bottles at the pub!'

(Cruschina 2012: 120-122)

(11) A: Alla fiera Gianni ha venduto la moto. at-the show John has sold the motorbike

B: La macchina alla fiera ha venduto, non la moto. the car at-the show has sold not the motorbike 'A: John sold his motorbike at the show. B: No, he sold his car at the show, not his motorbike.'

(adapted from Cruschina 2012: 143, (17))

Secondly, fronting with a mirative import cannot occur in embedded clauses, for example within the complement of a verb of saying (12). On the contrary, under the corrective interpretation such embedding, although slightly marked, is clearly possible (13).

(12) ??/*Non ci posso credere! Ha raccontato che due not CL.LOC can.1SG believe has.3SG said that two bottiglie ci eravamo bevuti! bottles CL be.IPF.1PL drunk.PL

(Cruschina 2012: 119, (ii))

(13) A: Gianni ha detto che ha venduto la moto. John has.3SG said that has.3SG sold the motorbike

B: No, ha detto che la macchina ha venduto. no, has.3SG said that the car has.3sG sold

'A: John said that he sold his motorbike.

B: No, he said that he sold his car.' 
Fronting and unexpectedness

We refer the reader to Cruschina 2012 for a syntactic analysis of these differences; what is relevant for our current purposes is that these syntactic contrasts identify the two types of fronting as grammatically distinct phenomena.

To summarize so far, we have provided both prosodic and syntactic evidence to the effect that MF constitutes a grammatical phenomenon on its own, rather than being just one of the pragmatically possible nuances of a general "focus fronting" structure. ${ }^{2}$ Hence, from this point on we will concentrate exclusively on MF; the next step will be to provide an explicit characterization of the mirative import.

\section{Unexpectedness as comparative likelihood}

The prosodic analysis has confirmed that the fronted constituent in MF bears narrow focus. The next question, then, is which role narrow focus plays in giving rise to the unexpectedness import. One interesting answer is provided by Partee's insight that unexpectedness involves a comparison between two different states of affairs:

Evidence for conceptualization of "other possible worlds" can be seen even at a prelinguistic level in any child or animal that can show surprise, since surprise signals mismatch between a perceived state of affairs and an expected state of affairs.

(Partee 1995: 326)

Notice that in MF, the fronted focus constituent occurs in the high periphery of the clause. In alternative semantics terms (Rooth 1992), the focus operator must attach at the clausal level in order to have the focus constituent in its scope, and the focus alternatives are thus exploited at the level of the proposition. The mirative import of this structure can then be taken to convey that the expressed proposition is unexpected when compared with at least one distinct focus alternative: there may be salient alternatives in the context, or else, relevant alternatives may be drawn from general background knowledge. (Note that we are not claiming that mirativity in general necessarily involves the comparison of focus alternatives, but that

2 On the other hand, Frey 2010 gives a unified analysis for German Ā-fronting, covering both the mirative and the corrective import. We leave for future research a crosslinguistic comparison between German and Italian fronting. 
this is the crucial contribution of focus in the case under exam; see Section 6 for more discussion.)

In order to formally model this idea, we will adapt a proposal by Grosz (2011), which characterizes unexpectedness in terms of the comparative likelihood of alternative propositions. ${ }^{3}$ Grosz's proposal is framed in Kratzer's theory of modality, which is based on two parameters:

(a) the modal base $B(w)$, which we can define (simplifying somewhat) as a set of possible worlds accessible from the evaluation world $w ; 4$

(b) the ordering source $O(w)$, a set of propositions ${ }^{5}$ which induces an ordering on the worlds of the modal base.

The ordering is determined by the relation between possible worlds defined in (14):

(14) For any two worlds $v, u \in B(w)$, $v \leq_{O(w)} u(v$ is at least as close as $u$ to the ideal represented by $O(w)$ ) if and only if all the propositions of $O(w)$ that are true in $u$ are true in $v$ as well.

[For all worlds $v$ and $u \in B(w): v \leq_{O(w)} u$ if and only if $\{p: p \in$ $O(w)$ and $u \in p\} \subseteq\{p: p \in O(w)$ and $v \in p\}$.]

On the basis of (14), it is possible to define the following relations between propositions (definition (15) adapted from Kratzer 2012: 41): ${ }^{6}$

(15) $p$ is at least as good a possibility as $q$ w.r.t. a modal base $B(w)$ and an ordering source $O(w)$ iff there is no world $u$ in $B(w)$ in which $q$ is true and $p$ is false which is closer to the ideal represented by $O(w)$ than all the worlds $v$ in $B(w)$ in which $p$ is true and $q$ is false. ${ }^{7}$

3 Grosz himself credits Villalta (2007) for the original insight.

4 More precisely, the modal base is yielded by a conversational background, i.e., a function which, for any evaluation world $w$, yields a set of propositions (the modal base is then determined by the intersection of such propositions).

5 The ordering source too is determined by a conversational background taking in input the evaluation world $w$.

6 Here we differ from Grosz (2011: §4.1.2), who adopts a different definition from Kratzer (1991).

7 "When comparing two propositions $p$ and $q$, we disregard the worlds $p$ and $q$ have in common and compare $p-q$ and $q-p$ by checking whether there is any world in $q-p$ that is higher ranked than every world in $p-q$. If not, $p$ is at least as good a possibility as $q$." (Kratzer 2012: 41) 
Fronting and unexpectedness

$$
\begin{aligned}
& {[\neg \exists u(u \in B(w) \& u \in q-p \&} \\
& \left.\left.\qquad \forall v\left((v \in B(w) \& v \in p-q) \rightarrow u<_{O(w)} v\right)\right)\right]
\end{aligned}
$$

(16) $\quad p$ is a better possibility than $q$ w.r.t. a modal base $B(w)$ and an ordering source $O(w)$ if and only if

(i) $\quad p$ is at least as good a possibility as $q$ w.r.t. $B(w)$ and $O(w)$;

(ii) $q$ is not at least as good a possibility as $p$ w.r.t. $B(w)$ and $O(w)$.

These definitions are completely neutral with respect to the nature of the modal base and of the ordering source: these determine the different flavours of modality that emerge in concrete examples. The modal notion that we need in order to analyse the mirative import is likelihood, and this is defined by a stereotypical ordering source:

(17) A stereotypical ordering source ('in view of the normal course of events') is a conversational background assigning to every world the set of propositions which represent the normal course of events in that world.

(Kratzer 1991: 645)

The stereotypical ordering source ranks the worlds in the modal base $B(w)$ according to how close they come to what constitutes the normal course of events in the world of evaluation $w$. Accordingly, if a proposition $p$ is a better possibility than another proposition $q$ with respect to a base $B(w)$ and a stereotypical ordering source $S O(w)$, we will say that $p$ is more likely than $q$ (with respect to $B(w)$ and $S O(w)$ ).

With this background, we can now characterize the mirative import that is associated with MF in the following way:

(18) The proposition expressed by the clause is less likely than at least one distinct alternative proposition with respect to a contextually relevant modal base and stereotypical ordering source. ${ }^{8}$

8 An unexpectedness import is also commonly associated with exclamative clauses. Zanuttini \& Portner (2003) argue that wh-exclamatives (e.g., What a cool day it was yesterday in New Delhi') perform domain widening, adding some potential values for the variable bound by the wh-phrase which are not included in the contextually given domain; this widening beyond the "usual" values may give rise, by implicature, to a feeling of surprise. This approach does not invoke the ranking of alternatives. Rett (2011) analyses exclamatives in terms of an illocutionary operator E-Force, which expresses that the propositional content was not expected by the speaker. As for wh-exclamatives, Rett shows that they always have a degree interpretation, and argues that they denote a property of degrees; for example, (ia) has the denotation in (ib) (Rett 2011: 40): 
We will discuss the nature of the modal base and of the ordering source in Section 5. To exemplify, let us consider the following instance of MF:

(19) Gianni è innamorato pazzo di Maria. Pensa un po'... Un anello John is in-love mad with Maria. think a little a ring di diamanti le ha regalato! of diamonds to-her.CL has given

'John is madly in love with Mary. Guess what! He gave her a diamond ring!'

Taking Rooth's (1992) focus operator $~$ to be attached on top of the clause, let us label $\alpha$ the constituent that it is adjoined to (20a). ${ }^{9}$ The ordinary semantic value of $\alpha-\llbracket \alpha \rrbracket^{o, g}$ in Rooth's notation - is the proposition that John gave Mary a diamond ring (2ob); the focus semantic value of $\alpha$-notated $\llbracket \alpha \rrbracket^{f, g}-$ is a set of alternative propositions of the form $Q$ ( $[\lambda x$.give(john, $x$, mary)]), where $Q$ is of the denotational type of the focussed constituent (20c). ${ }^{10}$ The focus operator introduces a free variable $C$, whose value is presupposed to be a subset of the focus semantic value of $\alpha$ (Rooth 1992: 93); the mirative import conveys that there is at least one member of this subset of alternative propositions which is more likely than the proposition that John gave Mary a diamond ring (20e). (Index $i$ stands for a world-time pair; for the sake of simplicity, we omit tense and the Davidsonian event position.)

(i) a. How tall John is!

b. $\lambda d$.tall $(j, d)$

The relevant proposition is obtained by existential closure of the degree variable at the discourse level: the exclamation then expresses that there is a degree $d^{\prime}$ such that the speaker had not expected the proposition $[\lambda d \operatorname{tall}(j, d)]\left(d^{\prime}\right)$. Here too, no ranking of alternatives is used to characterize the mirative import.

We believe that MF has to be analysed differently from exclamatives, because of at least two basic differences: first, contrary to $w h$-exclamatives, the propositional content of a clause hosting MF is asserted and not presupposed (see below the discussion around (24)); second, MF does not necessarily give rise to a degree interpretation based on some gradable property expressed by the focus phrase (see, e.g., (2), (3) above).

9 We will return briefly in Section 8 to the syntactic labels of this structure.

1o For simplicity, we take the denotation of the focus constituent a diamond ring to be of quantifier type. 
Fronting and unexpectedness

(20) a. $\left[\left[_{\alpha}[\text { A diamond ring }]_{\mathrm{F}}\left[\left(\mathrm{he}_{1}\right) \text { gave her }_{2} t\right]_{\alpha}\right] \sim C\right]$

b. $\llbracket \alpha \rrbracket^{o, g}=\lambda i$. $\llbracket$ a diamond $\operatorname{ring} \rrbracket^{o, g}(i)\left(\left[\lambda x\right.\right.$.give $_{i}($ john, $x$, mary $\left.\left.)\right]\right)$

(under an assignment $g$ such that $g(1)=$ john, $g(2)=$ mary)

c. $\llbracket \alpha \rrbracket^{f, g}=\left\{\lambda i . Q(i)\left(\left[\lambda x\right.\right.\right.$.give $_{i}($ john, $x$, mary $\left.\left.\left.)\right]\right): Q \in D_{\langle s,\langle e t, t\rangle\rangle}\right\}$

d. $C \subseteq \llbracket \alpha \rrbracket^{f, g}$

e. $\exists p \in C: p \neq \llbracket \alpha \rrbracket^{o, g} \& p$ is a better possibility than $\llbracket \alpha \rrbracket^{o, g}$ w.r.t. a relevant modal base and stereotypical ordering source.

The existential force of (18) requires $C$ to provide at least a minimal likelihood scale consisting of the expressed proposition and one distinct focus alternative. ${ }^{11}$ This is certainly the weakest possible definition of the mirative import, and it is in fact much weaker than Grosz's original proposal. ${ }^{12}$ The reason why we opt for this weaker formulation is that in the case of MF, there need not be any immediately salient set of alternatives: a hearer may perfectly interpret (19) even though this is uttered out of the blue - for example, as a comment on how madly in love with Mary John is - and there has been no previous mention of expensive or inexpensive gifts. ${ }^{13}$ The participants need only agree on the fact that there is at least one more likely alternative proposition, but they need not agree on any specific alternative (i.e., they may have different gifts in mind). ${ }^{14}$

11 On existential vs. universal quantification over alternatives, see Grosz (2011: 181).

12 Grosz (2011: §4.1.2) gives a different definition for the surprise reading in his analysis of unembedded dass-clauses in German, e.g., (i):

(i) Mein Gott, dass der nicht verschlafen hat!

my God that he not overslept has

lit. 'My God, that he didn't oversleep!'

paraphrase of exclamative reading: I'm shocked [that he didn't oversleep].

He assumes a set of contextually relevant alternative propositions which are ordered on a (speaker-related) scale $S$ of inverse likelihood; one proposition in the scale represents the contextually given threshold of likelihood. An operator $E X$ takes as arguments a scale $S$ and a proposition $p$, and (informally) expresses an emotion that captures the fact that $p$ is higher on the scale $S$ than all contextually relevant alternatives $q$ that are below the contextual threshold. The reasons for assuming a contextual threshold are not immediately relevant to our current purposes; therefore, we adopt a simpler (merely existential) definition of the mirative import. Clause 1 also has an optative reading, which is obtained by replacing the inverse likelihood scale with a bouletic scale (see below the discussion around (21)).

13 See also Cruschina 2012: 148-149.

14 In some contexts, the relevant alternatives are very constrained or even fully explicit (see, e.g., the exam examples (33), (39) and (40)), but this is not a necessary condition for the mirative import to be interpretable. This is another difference with respect to corrective 
Notice also that the fronting structure may come with a flavour other than surprise, for example disgust or discontent (see also Abeillé, Godard \& Sabio 2008 on French):

(21) Accidenti! Marina hanno invitato! damn Marina have.3PL invited

'Damn! (Of all people,) they invited Marina!'

This reading is usually accompanied by a "deprecation" marker, as exemplified above. We have not studied in detail the prosodic properties of focus fronting under this interpretation; one of the examples in our prosodic experiment clearly elicited a dislike evaluation, ${ }^{15}$ and the fronted focus displayed the same plateau profile which was observed in the other cases (see Section 2.1). Pending further investigation, we will tentatively assume - following again Grosz (2011) - that these cases are just like our MF, except for the fact that the interpretation involves a bouletic ordering source, rather than a stereotypical one (on ordering sources, see Section 5.3).

\section{The status of the mirative import}

The next question to be addressed concerns the interpretive status of the mirative import. Adopting the criteria proposed in Potts 2007a: 33 and Potts 2012: §2.1, we argue that it qualifies as a conventional implicature (CI) and that it belongs in a tier of meaning separate from the truth-conditional (at-issue) meaning.

A first indication of the CI status is non-deniability: by uttering a sentence with MF the speaker commits herself to the mirative import, and importantly, she cannot cancel it without making the sentence infelicitous:

focus, where there must be one salient alternative that gets corrected (see van Leusen's (2004) "Antecedent Condition").

15 See the Appendix for the list of the experimental items. 
Fronting and unexpectedness

(22) [Context: Lucy is telling news about her friend's new boyfriend]

Un anello di diamanti le ha regalato! \#Ma non c'è

a ring of diamonds to-her.CL has given! but not there's

niente di strano / \#ma la cosa non mi sorprende. $^{16}$

nothing of strange but the thing not me.CL surprises

'He gave her a diamond ring! \#But there's nothing strange about it / \#But that doesn't surprise me.'

Note also that, contrary to at-issue entailments, the mirative import is not affected by being in the scope of the polar question operator, as shown by example (7), repeated here as (23):

(23) Ma domani al mare andate?

but tomorrow to-the seaside go.2.PL

'Are you going to the seaside tomorrow?'

Sentence (23) does not entail the proposition that the salient group including the addressee(s) $\left(x \oplus a_{C}\right)$ is going to the seaside tomorrow (at-issue content), but it does convey that there are more likely alternatives of the form ' $x \oplus a_{C}$ are going to place $y$ tomorrow" (see Section 4.1 for details).

Furthermore, two types of evidence support Potts's multidimensional analysis, showing that the interpretation of MF yields a pair of an at-issue proposition and a CI proposition. Note first that the propositional content of a sentence containing MF is asserted by the speaker: this is shown by the fact that it can be directly denied by the interlocutor, as in $(24 \mathrm{~B})$, a reply to a variation of (19). ${ }^{17}$

16 The continuation in (22) is felicitous if the speaker makes it clear that she is expressing a dislike evaluation rather than an evaluation of unexpectedness; similarly, the example (21) above would also be compatible with the same kind of continuation. In the spontaneous examples that we have observed, the context usually disambiguates the intended reading (e.g., by concomitant expressions of surprise or deprecation). As already mentioned, we cannot tell at this point whether these two nuances are also distinguished by a different prosodic profile.

17 We borrow the denial test from Rett 2011: (5). 
Bianchi \& Bocci \& Cruschina

(24) A: Pensa un po': un anello di diamanti le ha regalato! think a little: a ring of diamonds to-her.CL has given

B: Niente affatto! (Chi ti ha detto questa assurdità?) nothing at-all! who you.CL has told this absurdity

'A: Guess what! He gave her a diamond ring!

B: You're wrong! (Who told you this absurd thing?)'

Although speaker B rejects the truth-conditional content of A's assertion, he is not thereby committed against the mirative import: this shows that the at-issue meaning and the CI-meaning belong to two separate dimensions, that is, they are treated independently in the interpretation process.

The reverse dissociation can also be observed: in (25), speaker B accepts the propositional content of A's assertion, while rejecting its mirative import:

(25) A: Pensa te! Un anello di diamanti le ha regalato! think you a ring of diamonds to-her.cL has given

B: Non c'è niente di strano.

Not there's nothing of strange

'A: Just think about it! He gave her a diamond ring!

B: There's nothing strange about that.'

One additional argument for multidimensionality can be based on ellipsis. To illustrate, consider the following example, featuring an expressive epithet (Potts 2012: (14)):

(26) A: I saw your fucking dog in the park.

B: No, you didn't. You couldn't have. The poor thing passed away last week.

Speaker B's utterance contains two instances of VP-ellipsis, and the content of the elliptical VPs must be parallel to that of the antecedent VP in speaker A's utterance. Crucially, what is parallel is just the ordinary denotation of that VP (the property of seeing speaker B's dog in the park), but not the expressive content introduced by the modifier fucking contained in the antecedent VP. This shows that the CI content of the expressive modifier is separate from the descriptive content of the containing VP.

A similar separation can be observed in the case of MF. In (27), the elliptical predicate in B's reply is parallel to the descriptive content of the predicate in A's assertion, yet B explicitly rejects A's mirative implicature: 
Fronting and unexpectedness

(27) A: Pensa te! Un ritratto stile Warhol si è fatto fare! think.IMP you a portrait style Warhol REFL is made make

B: Io pure. Che c'è di strano?

me too what there is of strange

'A: Guess what! He got himself a Warhol-style portrait!

B: Me too. What's strange about that?'

These properties, taken together, characterize the mirative import as a conventional implicature in the sense of Potts. ${ }^{18}$

\subsection{Compositional analysis of MF}

We have not yet made clear how the mirative implicature is actually introduced. In principle, it could be directly introduced by an illocutionary operator (see Grosz 2011, Rett 2011, Rett \& Murray 2013 for similar proposals; see also Section 6 for discussion). Recall, however, that MF can occur both in assertions and in yes-no questions: we would then have to assume that the mirative import can be optionally introduced by two different illocutionary operators.

A closer look at yes-no questions gives us evidence against such a direct association. Consider (28):

\section{Marina hanno invitato? \\ Marina have.3PL invited}

'Did they invite Marina?'

In a Hamblin-type approach, yes-no questions denote the set consisting of the proposition $p$ denoted by the sentence radical and its complement: $\{p, \neg p\}$. But note that the mirative import carried by (28) is interpreted with respect to the focus alternatives of the proposition $p$, and not of its complement: namely, (28) conveys that there are more likely alternatives of the form "they invited $x$ ". Assuming that the polar set is generated by a Polar Question

18 A conceptually distinct possibility would be to analyse the mirative import as a conversational implicature. On this view, all that is grammatically encoded is that the focus alternatives are defined at the propositional level (since the Focus operator is adjoined on top of the clause); then, in each particular context, the hearer identifies either the mirative import or the corrective import as the most plausible way to embed the sentence in the overall discourse structure (see Asher 2004). However, the empirical evidence provided in Section 2, as well as the lack of cancellability, undermine this view. 
operator which takes in input the proposition denoted by the sentence radical, we are led to hypothesize that the mirative implicature is introduced at a compositional level below the operator, where the complement proposition $\neg p$ is not yet available.

On the other hand, the implicature must be introduced at a level not lower than the attachment site of the focus operator, because its interpretation relies on a comparison between the proposition expressed by the sentence radical and at least one focus alternative. The focus operator introduces a free variable $C$, whose value is constrained to be a subset of the focus semantic value of the proposition; this subset $C$ constitutes the quantificational domain of the existential quantifier of the implicature.

We therefore define an operator F-IMP ${ }_{C}$ (for: focus-based implicature), which takes in input the ordinary semantic value of the immediately lower compositional layer and exploits as a restriction the set of alternatives $C$ introduced by the focus operator, returning

(a) the original proposition (of type st ${ }^{a}$ : at-issue content) and

(b) a CI-proposition (of type $\mathrm{st}^{c}$ ).

The two components of meaning are here separated by the symbol $\bullet$, following Potts's notation (and adopting his rule of CI-application): ${ }^{19}$

(29) $\llbracket \mathrm{F}^{-\mathrm{IMP}_{C} \rrbracket} \rrbracket \lambda p_{\langle s, t\rangle} \cdot p \bullet\left(\exists p_{\langle s, t\rangle}^{\prime} \in C\right)\left(p^{\prime}\right.$ is a better possibility than $p$ w.r.t. a relevant modal base and stereotypical ordering source).

For convenience, we will call $p$ the "prejacent proposition" and the conventionally implicated proposition "mirative proposition". Given the hypothesized compositional layers - for convenience indicated in (30) by arbitrary Greek letters labelling the opening and closing brackets - the interpretation of the sentence radical of question (28) will be as in (31) (again, index $i$ stands for a world-time pair; we ignore for simplicity the temporal information and the Davidsonian event position and, assuming the proper name to be a rigid designator, we directly use its extension):

$$
\left.{ }_{X} \mathrm{~F} \mathrm{IMP}_{C}\left[{ }_{\phi}\left[{ }_{\alpha} \mathrm{XP}_{F} \ldots t_{\alpha}\right] \sim C_{\phi}\right]_{X}\right]
$$

19 This differs from Grosz's $E X$ operator, which maps a truth-conditional meaning into a onedimensional expressive meaning (Grosz 2011: §4.1.6). Here the output is two-dimensional because, as shown above, the at-issue content of a clause hosting MF is asserted or questioned. 
Fronting and unexpectedness

(31) a. $\llbracket\left[{ }_{\alpha}[\text { Marina }]_{\mathrm{F}}\left[\text { pro }_{1} \text { hanno invitato } t\right]_{\alpha}\right] \rrbracket^{o, g}=\lambda i$.invite ${ }_{i}(\mathrm{a} \oplus \mathrm{b}, \mathrm{m})$ (where, for the contextually determined assignment $g, g(1)=\mathrm{a} \oplus \mathrm{b}$ )

b. $\llbracket\left[\left[_{\alpha}[\text { Marina }]_{\mathrm{F}}\left[\text { pro }_{1} \text { hanno invitato } t\right]_{\alpha}\right] \rrbracket^{f, g}=\right.$

$$
\left\{\lambda i \text {.invite }_{i}(\mathrm{a} \oplus \mathrm{b}, x): x \in D_{e}\right\}
$$

c. $\llbracket C \rrbracket^{g} \subseteq\left\{\lambda i\right.$.invite $\left.(\mathrm{a} \oplus \mathrm{b}, x): x \in D_{e}\right\}$

d. $\llbracket \phi \rrbracket^{o, g}=\llbracket \alpha \rrbracket^{o, g}=\lambda i$ invite ${ }_{i}(\mathrm{a} \oplus \mathrm{b}, \mathrm{m})$

e. $\llbracket \chi \rrbracket^{o, g}=\llbracket \mathrm{F}-\mathrm{IMP}_{C} \rrbracket^{o, g}\left(\llbracket \phi \rrbracket^{o, g}\right)$ $=\lambda$ i.invite ${ }_{i}(\mathrm{a} \oplus \mathrm{b}, \mathrm{m}) \bullet\left(\exists p^{\prime} \in \llbracket C \rrbracket^{g}\right)\left(p^{\prime}\right.$ is a better possibility than $\lambda i$.invite ${ }_{i}(\mathrm{a} \oplus \mathrm{b}, \mathrm{m})$ w.r.t. a relevant modal base and stereotypical ordering source)

It is important to stress that the mirative implicature can be properly interpreted only on the basis of a non-singleton focus semantic value: this is why we have dubbed it focus-based implicature. We return in Section 8 to the linguistic implementation of the implicature trigger.

\section{The role of the context}

\subsection{Which modal base?}

In (18) we characterized the mirative import of MF in terms of a modal relation of comparative likelihood. The next question to be addressed is which modal base is used to interpret it. Prima facie, it seems natural to assume that the modal base is constituted by the set of worlds that are doxastically accessible to the speaker at the time and world of utterance. This would correspond to the idea that the mirative import is the expression of the speaker's surprise, as is generally assumed since DeLancey's first characterization. ${ }^{20}$

However, this natural assumption leads to a paradox in cases of assertion like (19) above, repeated here as (32):

20 Despite being generally associated with the speaker's surprise (DeLancey 1997, 2001) in her survey of the central properties of the mirative systems across languages, Aikhenvald (2012) points out that mirativity may also reflect the addressee's or the conversation participants' surprise or unexpectedness. In !Xun, for example, the mirative marker, which can occur both in statements and in questions, can also mark information that is new and surprising to the addressee or to the audience, so that an event is not necessarily marked as unexpected to the speaker alone, "but to anyone involved in the conversation" (Aikhenvald 2012: 448, citing König 2013). See also note 26 and Section 6 for more discussion. 
Bianchi \& Bocci \& Cruschina

(32) Un anello di diamanti le ha regalato!

a ring of diamonds to-her.CL has given

'He gave her a diamond ring!'

By (18), the mirative import conveys that the expressed proposition is less likely than some alternative propositions. Note that in order for this to hold, the expressed proposition cannot be true in all the worlds of the modal base: if this were the case, no other proposition could be a better possibility. (Let $p_{o}$ be the expressed proposition and $p_{f}$ an arbitrary focus alternative. For $p_{f}$ to be a better possibility than $p_{o}$, it must be the case that $\neg\left(p_{o}\right.$ is as good a possibility as $\left.p_{f}\right)$ (by (16ii) above), that is, $\neg(\neg \exists u(u \in$ $\left.\left.B(w) \& u \in p_{f}-p_{o} \& \forall v\left(\left(v \in B(w) \& v \in p_{o}-p_{f}\right) \rightarrow u<_{O(w)} v\right)\right)\right)$; but if every world in $B(w)$ is a $p_{o}$-world, there can be no world $u$ such that $u \in p_{f}-p_{o}$; hence, $p_{f}$ cannot be a better possibility than $p_{o}$.) The paradoxical conclusion is that, for the mirative import to be interpretable, the speaker could not believe the proposition that she is asserting.

As a solution to this paradox, we might assume a weak version of the Gricean quality maxim, such that the speaker's asserting $p$ does not require that she believes $p$, but only that she does not believe $p$ to be false. ${ }^{21}$ But this solution turns out to be insufficient if we take a conversation-oriented perspective.

In the dynamic approach initiated by Stalnaker 1978, the crucial notion is not individual belief, but rather, public acceptance: the conversational community shares a common ground of propositions that are mutually taken to be accepted by every participant. ${ }^{22}$ As stressed by Gunlogson (2003) and Farkas \& Bruce (2009), an act of assertion has a double effect. On the one hand, a speaker who makes an assertion immediately commits herself to the truth of the asserted proposition: this becomes part of her public discourse commitments. On the other hand, the speaker proposes that the asserted proposition is to be entered in the common ground: if the other participants accept her assertion, the proposition becomes a joint commitment of the conversational community from that point on.

If we then shift from individual beliefs to public commitments, the relevant modal base would be the set of worlds that are compatible with the

21 See, e.g., Chierchia (2006: §3.1).

22 That is, every participant behaves as if she accepted the truth of such propositions, and expects the others to do the same. On acceptance, see Stalnaker (1984: 79ff.). 
speaker's discourse commitments at the moment of utterance. ${ }^{23}$ Recall now from (24) above that a declarative sentence hosting MF is asserted. By asserting it, the speaker becomes publicly committed to the expressed proposition: it follows that the asserted proposition is true in all the worlds of this modal base and, once again, no alternative proposition can be a better possibility.

One possible way out could be to assume a "two-stage" interpretation. Suppose that the mirative import associated with an asserted proposition $p$ is interpreted with respect to the modal base characterized by the speaker's discourse commitments minus the asserted proposition itself, that is, the speaker's commitments at the stage immediately preceding the assertion. At that time, $p$ is not (yet) true in every world of the modal base (nor is any other focus alternative: for an assertion of $p$ to be felicitous, $p$ must answer a still unsolved question, see Roberts 2012): hence, with respect to this modal base, some focus alternative may well be a better possibility than $p$.

But even this solution turns out to be insufficient. To see this, consider the following scenario: Mary's parents are talking about an exam that Mary has just taken, where the maximum score is thirty with distinction. Mary's mother, after talking to Mary over the phone, asserts that Mary got the top score, but her husband does not accept this claim. They check the score published on the university website and Mary's mother, pointing at the screen, utters:

(33) Te l' avevo detto: trenta e lode le hanno
you.CL it.CL had.1SG said thirty with distinction her.CL have.3PL
dato!
given

'What did I tell you? She got thirty with distinction!'

This is a felicitous instance of MF: ${ }^{24}$ but note that the speaker had previously committed herself to the truth of the proposition that Mary got the top score. In this case, the hypothetical two-stage interpretation will not help.

Note that, on the other hand, the use of MF is infelicitous when the propositional content of the assertion is already presupposed by all the

23 This is the set $C S_{s, i}$ in Farkas \& Bruce (2009); see Section 5.2 for details.

24 Note that (33) cannot be an instance of corrective focus fronting, because Mary's father has not asserted any alternative proposition of the form 'Mary got score $x$ '. As a matter of fact, the assertion in (33), contrary to real corrections, cannot be introduced by the negative particle no or an adversative adverb like actually. 
participants. ${ }^{25}$ Suppose that Mary has just come home and informed her parents that she got the top score on the test. As soon as Mary leaves the room, one of them utters:

$$
\begin{aligned}
& \text { \#Non posso crederci: trenta } e \text { lode le hanno dato! } \\
& \text { Not can believe-it thirty with distinction her.CL have.3PL given }
\end{aligned}
$$

'I can't believe it: she got thirty with distinction!'

This is not a felicitous utterance, even though it may convey something new - namely, an attitude of surprise about the score that Mary has just reported. The crucial difference between (33) and (34) is that in (33) the asserted proposition is an individual commitment of one participant, whereas in (34) it is already accepted as true by both participants. Given our previous argument, the infelicity of mirative fronting in (34) follows immediately if the modal base that is used to interpret the mirative import is the set of worlds characterized by the joint commitments of the conversational community at the moment of utterance. ${ }^{26}$

\subsection{The informative components}

The above argument has led us to identify the relevant modal base with the context set, namely the set of possible worlds in which all the propositions presupposed by the conversational community are true. In order to make this idea explicit, let us reconsider in more detail the structure of the discourse context, starting from the Stalnakerian picture informally introduced in Section 5.1.

At any given point of a conversation - conventionally indicated by an index $i$ - let the common ground $C G_{i}$ of a context be the set of propositions that are mutually taken to be accepted by all the conversational participants. Let the context set $C S_{i}$ be the set of possible worlds that are compatible with all the information in $C G_{i}$; technically, $C S_{i}$ is obtained by the intersection of all the propositions of $C G_{i}\left(\cap C G_{i}\right)$. If a speaker $s$ asserts a sentence at $i$, she proposes that the expressed proposition $p$ be added to $C G_{i}$. If her assertion is accepted by the other participants, the proposition is added

25 An anonymous reviewer points out to us that in this respect, MF differs from the factive predicate It is surprising that $p$, where the proposition expressed by the complement clause is presupposed. At this point, it is unclear to us how the difference should be characterized. 26 This conclusion concurs with Zimmermann's (2007) proposal that unexpectedness is defined by the mutually recognized expectations of the speaker and the hearer(s). 
Fronting and unexpectedness

to $C G_{i}\left(C G_{i+1}=C G_{i} \cup\{p\}\right)$ and consequently, it discards from $C S_{i}$ all the possible worlds in which $p$ is not true: this yields a "shrunk" context set $\left(C S_{i+1}=C S_{i} \cap p\right)$.

Various authors have stressed that this picture is too radically communitarian, in that it does not provide a way to model situations of disagreement, and moreover, it cannot represent any asymmetry between the participants with respect to informational needs or aims. ${ }^{27}$ To this effect, the context must also separately represent the discourse commitments of each individual participant.

The structured context proposed by Farkas \& Bruce (2009) incorporates both the individual and the communitarian perspectives. This system contains some components in addition to the CG:

- The Table is a stack structure which records, at any given point, what constitutes the immediate goal of the conversation. Whenever an assertion is made or a question is asked, it is pushed on top of the stack: in the case of an assertion, the immediate goal is to decide whether all the participants accept it; in the case of a question, the immediate goal is to answer it. ${ }^{28}$

- The context also contains, for every participant $x$, an individual discourse commitment set $\left(D C_{x, i}\right)$, consisting of those propositions that $x$ has publicly committed herself to, but which have not been accepted by the other participants.

The total discourse commitments of $x$ at index $i$ consist of the set of individual commitments of $x$ plus the propositions of the Common Ground $\left(D C_{x, i} \cup C G_{i}\right)$; the intersection of all these propositions yields a context set relative to participant $x\left(C S_{x, i}\right)$.

When a speaker $s$ asserts a proposition $p$ at index $i$, the following updates occur:

(i) $p$ is added to the speaker's discourse commitments $\left(D C_{x, i} \cup\{p\}\right)$;

(ii) $\{p\}$ (together with the declarative sentence that conveys it) is pushed on the Table, and thus becomes the current conversational goal.

27 See, e.g., Gunlogson 2003 and Ginzburg 2012: §1.

28 The Table is a generalization of Roberts's (2012) QUD stack. For the sake of compactness we omit one further component, the Projected Set, which is not crucial for our argument. 
However, $C G_{i}$ is updated by $p$ only after all the participants have confirmed the assertion. ${ }^{29}$

Crucially, for an assertion of $p$ to be felicitous, $p$ cannot be already positively decided in the current context set $C S_{i}$ - namely, it cannot be true in all the worlds of $C S_{i}$ - because if this were the case, the update effect of the assertion would be vacuous. The proposition cannot be negatively decided in $C S_{i}$ either, because in that case the speaker would be making an assertion that is inconsistent with $C G_{i}$, and the update effect of her move would lead to an empty CS. ${ }^{30}$ Therefore, the asserted proposition must be undecided with respect the current $C S_{i}$.

In this way, Farkas \& Bruce's componential system allows us to model an intermediate stage of the conversation in which an asserted proposition is on the Table, but is still undecided in $C S_{i}$. This provides us with a suitable modal base to properly interpret the mirative import (18):

(35) For a sentence hosting MF which is asserted at $i$, the modal base with respect to which likelihood is calculated is the context set $C S_{i}$, as defined by the conversational common ground $C G_{i}$ at the moment of utterance $i$, prior to acceptance of the assertion.

Since the expressed proposition $p$ is undecided in $C S_{i}$, it is possible that some distinct focus alternative is more likely than $p$ (with respect to a stereotypical ordering source, to be discussed below). Recall also that MF can appear in yes-no questions (see examples (7)/(23) and (28)). In Farkas \& Bruce's analysis, yes-no questions introduce on the Table the polar set consisting of the proposition $p$ denoted by the sentence radical and its complement $\{p, \neg p\}$; crucially, at the point where the question is asked, neither $p$ nor $\neg p$ are in the current $C G_{i}$ : since $p$ is undecided in $C S_{i}, C S_{i}$ constitutes a suitable modal base in this case as well.

Principle (35) provides a natural and conceptually economical solution to the problem of the modal base, but note that it implies a radical shift of perspective: it defines the mirative import not with respect to the speaker's individual beliefs (or commitments), but rather, with respect to the shared commitments of the conversational community.

29 Assertion confirmation is a default move, and it may remain tacit. 30 This is just Stalnaker's (1978) Condition I on assertion. 
Fronting and unexpectedness

\subsection{Which ordering source?}

Let us now consider the second modal parameter that is required to interpret the mirative import, namely the ordering source.

Consider a slight modification of our earlier scenario (Section 5.1): Mary has to pass an exam for which the maximum score is thirty with distinction. The speaker's expectations diverge from those of her interlocutor: the speaker expects that Mary will get the top score, whereas her interlocutor believes that Mary will get a lower score, around 27-28. Later on, the speaker triumphantly reports to her interlocutor the fact that Mary obtained the top score in the following way:

(36) Lo dicevo io: trenta e lode le hanno dato!

it.CL said.1SG I thirty with distinction her.CL have.3PL given

'What did I say? She got thirty with distinction!'

Here, MF is felicitous even though it is the hearer's expectations that are violated, rather than the speaker's. This shows that the ordering source is not necessarily anchored to the speaker. ${ }^{31}$

On the other hand, (37) below would be a felicitous assertion in a context where all the participants expected Mary with some certainty to get 29, for example, because she failed exactly one question out of thirty:

(37) Che strano: trenta e lode le hanno dato!

how strange: thirty with distinction her.CL have.3PL given

'How strange: she got thirty with distinction!'

In this case, the mirative import is relative to the shared expectations of the whole conversational community.

These observations suggest that the mirative implicature can potentially be interpreted with respect to a variety of ordering sources. ${ }^{32}$ The obvious hypothesis is that the ordering source is a contextual parameter whose value is supplied by the context, reducing this variation to a standard case of context-dependence.

31 The violation of the hearer's expectations is also attested in the case of the mirative proper, at least in some languages: see Aikhenvald 2012: 448.

32 Recall also that in certain examples the ordering source is bouletic rather than stereotypical (see (21) above). 
A less obvious hypothesis is to assume that the context actually leaves the modal parameter indeterminate, allowing for a flexible interpretation, as suggested by von Fintel \& Gillies (2011) in their analysis of epistemic might. The authors note that in a dialogue like (38), the epistemic modal base for the interpretation of the modal cannot be unitary throughout the exchange: on the one hand, A's assertion is only justified with a speaker-centric modal base, but on the other hand, B's negative reply would not make sense if the denied modal proposition still had a modal base exclusively anchored to A:

(38) [Alex is aiding Billy in the search for her keys.]

A: You might have left them in the car.

B: No, I still had them when we came into the house.

(von Fintel \& Gillies 2011: 114-115, (12)/(14))

The proposed solution is to allow these assertions to be interpreted in relation to a cloud of contexts (one for each possible resolution of the modal parameter), thus "putting into play" a number of distinct propositions, while requiring that the asserting speaker be in a position to assert one of the propositions that she is putting into play. Thus, A's assertion is justified on the basis of a speaker-centric resolution anchored to A only, while $B$ 's rejection is justified on the basis of either a speaker-centric resolution anchored to $\mathrm{B}$, or a communitarian resolution anchored to $\mathrm{A}+\mathrm{B}$.

An interesting feature of the conversational dynamics exemplified in (38) is that the indeterminacy in the resolution of the modal parameter allows the interlocutors to converge on a shared modal base. B's rejection is based on some counter-evidence available to B only, but this incompatibility will carry over to a "group" contextual resolution in which the modal base consists in the intersection of A's and B's information states (von Fintel \& Gillies 2011: (11)); by communicating her counterevidence to A, B ensures that the two information states converge in such a way that A will be led to accept her denial.

A similar dynamics seems to be going on in our earlier example (25), repeated here as (39) (see also example (27)): 
Fronting and unexpectedness

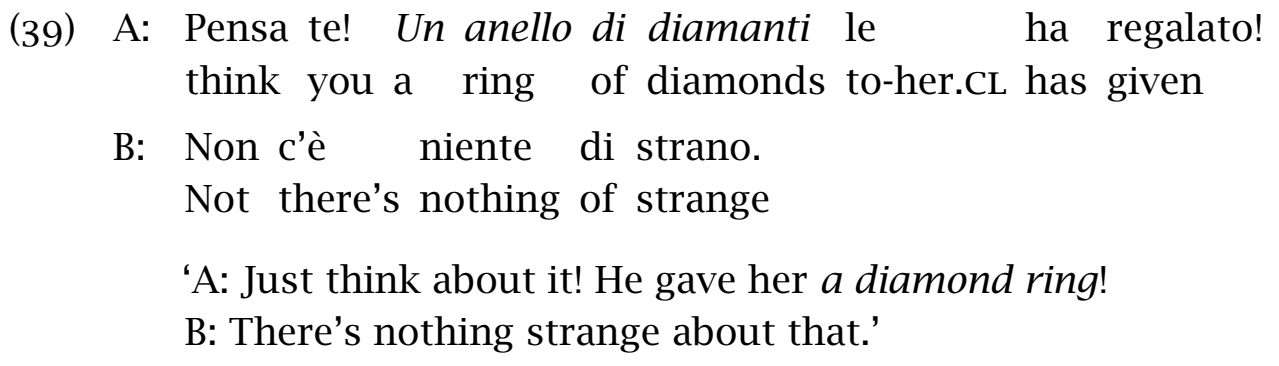

Here, speaker B rejects the mirative implicature of A's assertion, while accepting its informative content. The rejection manifests the fact that the modal parameters of the two interlocutors are not fully aligned. We can hypothesize that the ordering source for A's mirative implicature is underspecified in von Fintel \& Gillies's sense: speaker A conveys the implicature on the basis of her own stereotypical ordering source, and this serves as a ballon d'essai prompting a reaction on speaker B's part, which expresses whether the mirative proposition is true with respect to B's ordering source as well. ${ }^{33}$ Thus, this type of negotiation has the potential double effect of (a) admitting the mirative proposition in the common ground, or rejecting it, and (b) making explicit the alignment, or disalignment, of the modal parameters.

As we have argued at length, a sentence with MF has both informative content (the prejacent proposition, which is asserted or questioned) and evaluative content (the mirative proposition). The negotiation described above shows that the mirative proposition indeed qualifies as a speaker commitment, which can be accepted or rejected by the interlocutor (independently of the speaker commitment to the prejacent proposition, in the case of assertion).

We propose that a commitment whose interpretation is based on (a cloud of) ordering sources qualifies as an evaluative commitment. While the main purpose of informative commitments is to rule out certain possible worlds, the purpose of an evaluative commitment is to signal the (in)congruence between the described state of affairs and a given ideal (stereotypical, bouletic, or what have you). Crucially, the mirative proposition can be negotiated and, when it is accepted by all the interlocutors, it becomes a joint evaluative commitment.

33 A distinct possible reason for the rejection is that the modal bases, rather than the ordering sources, are not aligned: this will be the case when the common ground is defective in Stalnaker's (1978) sense (for instance, speaker A may asymmetrically lack the information that Mary's new boyfriend is a millionaire; when this information is made explicit by B, A may well agree that it is perfectly normal for a millionaire to buy such an expensive gift). 
In this respect, evaluative commitments differ from the expressive meaning carried by an epithet like fucking, exemplified in (26) above. Note that the hearer can correctly interpret an emotive expressive even if she does not have any other information about the emotional state expressed by the speaker: contrary to MF, here the interpretation involves neither a modal base nor an ordering source. Moreover, expressive meaning does not give rise to the kind of negotiation described above: if the hearer does not share the speaker's emotional state towards a given entity, the speaker will not try to get the hearer to share it simply by using an epithet like fucking.

In view of these differences, it seems safer to conceive of Potts's (2007b, 2007a) expressive meaning as distinct from our evaluative commitments. ${ }^{34}$ This is not to say that the two types of meaning cannot be intertwined in a single utterance: as a matter of fact, MF structures are quite hospitable towards emotive expressives, as shown in (40):

(40) Pensa te! Con quell' oca di Mariangela si è messo! think you with that goose of Mariangela self.cL is put

'Guess what! He’s dating that silly goose, Mariangela!'

We believe that this is because instances of MF like (40) actually involve a bouletic ordering source, rather than a stereotypical one, and indicate the speaker's approval or disappointment at the state of affairs described (see above the discussion around (21)). A bouletic evaluation (either positive or negative) is very naturally associated to the expression of a heightened emotional state (correspondingly positive or negative); we suspect that this is the main reason why there is a prevailing tendency to conceive of MF as expressing a speaker attitude. In our view, the evaluation proper can coexist with the immediacy of a heightened emotional state, but should not be identified with it.

One problem that we have to leave open is the relationship between our evaluative implicatures and the so called "predicates of personal taste" (see Lasersohn 2005, Stephenson 2007, Moltmann 2009, Pearson 2012). A lexical predicate like surprising, which conveys a surprise import, seems to be a predicate of personal taste: here, contrary to MF, the "evaluative" component is clearly part of the at-issue meaning. The approaches by Lasersohn (2005) and Stephenson (2007) emphasize the perspective-dependence of such predicates, and the fact that they give rise to "faultless disagreement", whereas

34 Although both pertain, by hypothesis, to the CI dimension. 
Fronting and unexpectedness

Moltmann's and Pearson's approaches emphasize their inherent genericity, and relate it to a first person-oriented interpretation. ${ }^{35}$ It is unclear to us at this point whether the interpretation of surprising/be surprised at involves an ordering source, which is the hallmark of evaluative meaning in the way we defined it.

\section{Mirativity in a wider perspective}

Our account of MF relies on two basic claims: firstly, its mirative import is encoded in a layer distinct from the illocutionary layer; secondly, it is intrinsically dependent on a focus structure. These two claims are not shared by other recent analyses of mirative phenomena, hence they seem to be at odds with an attempt at giving a unified analysis of mirativity.

As for the first point, the (co-)existence of different semantic analyses which encode the mirative import either at the illocutionary level or below it is not as problematic as it may seem at first sight, in light of the fact that a similar dichotomy characterizes the literature on evidentials. Indeed, depending on the relationship with epistemic modality, two types of evidential have been identified, which have in turn inspired two different kinds of analysis (see Murray 2010: §3): (i) illocutionary evidentials, as in Cuzco Quechua (Faller 2002, 2007), and (ii) epistemic evidentials, as in German (Faller 2007) and St'át'imcets (Matthewson, Rullmann \& Davis 2008), which have been interpreted as epistemic modals with an evidential presupposition restricting the modal base. The first analysis generally acknowledges that evidentiality is a category distinct from epistemicity, even though a certain degree of overlapping is admitted in the subfield of inferential evidentiality, which might be interpreted as a type of epistemic modality (Faller 2002; see also Dendale \& Tasmowski 2001, Plungian 2001). On the contrary, the second type of analysis tends to assume that the two categories of evidentiality and epistemicity cannot be entirely distinct (see in particular Matthewson, Rullmann \& Davis 2008).

In light of this, it is perhaps less surprising that in different cases, the mirative import can be introduced directly by an illocutionary operator (Grosz

35 "To say that the cake is tasty is to say that the cake is tasty to every (contextually restricted) individual with whom I identify. The identify with relation is intended to model a notion of empathy and is therefore reflexive: I always empathize with myself. In normal conversation, we empathize with our interlocutors [...]" (Pearson 2012: §3.3). 
2011, Rett 2011, Rett \& Murray 2013) or as a conventional implicature at a lower level, as proposed here (and in Frey 2010).

Pursuing further the parallelism with controversies concerning evidentiality, it is also worth emphasizing that languages differ with respect to the use of evidentials proper or evidential strategies (Aikhenvald 2004); in a similar way, they may also differ as for the encoding of mirativity, resorting to a range of grammatical devices, strategies and structures, which are yet to be fully explored and described. We have proposed that Italian mirative fronting is one such a structure where the interpretation of mirativity requires a set of focus alternatives: this is meant to explain why in many different languages a mirative flavour arises in connection with the marking of a constituent as narrowly focussed. However, we are not claiming that focus is necessarily involved in all mirative structures and strategies across languages: in other cases, the interpretation could rely on a set of expectations (in the sense of Rett \& Murray 2013) which is not related to focus structure in any direct way (see Section 6.2 for more discussion of Rett \& Murray's proposal).

Despite these parallelisms between the two domains, we ultimately remain agnostic as to the relationship between mirativity and evidentiality. Several studies have highlighted that indirect evidentials may have a mirative function or overtone (DeLancey 1997, Lazard 1999, 2001, Aikhenvald 2004, Peterson 2010, Rett \& Murray 2013); however, according to DeLancey (1997, 2001) and Aikhenvald (2004, 2012), the two grammatical categories must be viewed as distinct: while evidentials signal the source of information, mirativity marks surprise as a result of unexpected information irrespective of the source. Once again, it is quite conceivable - at least at the present stage of understanding - that mirativity overlaps with evidentiality in some languages or structures, but not in others: in the same way as there are evidential systems that do not express mirativity, there are also mirative systems that do not express evidentiality (Aikhenvald 2004: 195).

As for our case study, Italian mirative fronting does not present evidential readings and it is unrelated to evidential strategies marking the source of information or the way knowledge has been acquired. Note that Italian does not possess a grammatical system of evidential markers, but only evidential extensions of non-evidential categories: the future and imperfect indicative and the conditional, as well as the modal 'dovere + infinitive' construction, have developed semantic extensions or overtones that may be related to the evaluation or indication of the information source, similar to inferential evidentials (see, e.g., Squartini 2008, 2010). Crucially, however, none of these 
Fronting and unexpectedness

strategies expresses mirativity, and none of them is necessarily associated with mirative fronting.

In the following subsections, we compare our proposal with two recent analyses of mirative phenomena; this comparison will allow us to further clarify the reason for our analytical choices.

\subsection{Torres Bustamante (2012)}

Torres Bustamante (2012) analyses the mirative use of the Imperfect in Spanish generic or stative sentences (see also Torres Bustamante 2013):36

(41) ¡Juan fumaba!

Juan smoke.PAST.IMP.3SG

'Juan smokes!'

(Torres Bustamante 2012: 347, (1))

Crucially, with this structure the speaker expresses her surprise at a present state of affairs. The author argues that the past tense conveyed by the Imperfect does not temporally locate the state described in the clause, but rather, it shifts backward the temporal parameter of the doxastic modal base representing the speaker's beliefs: in this way, surprise is defined with respect to the speaker's past beliefs up to the discovery time in which she realizes that the actual state of affairs (John's being a smoker) contradicts her previous beliefs.

Similarly to Grosz (2011), the mirative import of the Spanish Imperfect is defined in terms of the relative likelihood of the asserted proposition $q$ and one relevant focus alternative (which is constrained to having the same aspectual value as $q) .{ }^{37}$ Specifically, it is characterized as non-at-issue content conveyed by a CP-level operator $M$, conveying that the worlds in which the asserted proposition is true are ranked below the worlds in which a distinct focus alternative is true. This operator takes in input a doxastic modal base $p$ - representing the speaker's beliefs at a past time, as discussed above - and conveys (a) that the proposition $q$ expressed by the sentence radical is true in the evaluation world $w_{@}$, and (b) that the worlds $w$ of the modal base in which $q$ is true are ranked below the worlds $w^{\prime}$ in which one salient alternative $q^{\prime}$ is true, where $q^{\prime}$ is supported by the modal base $p$ :

36 The author also discusses a mirative use of the Pluperfect in Andean Spanish, which we will not consider here for reasons of space.

37 Note however that, contrary to mirative fronting, here no single constituent bears narrow focus, but the whole clause is in focus (Torres Bustamante 2012: (20)). 


$$
\begin{aligned}
M_{o p}=\lambda p \lambda q \cdot \exists q^{\prime}: q^{\prime} \neq q \wedge C\left(q^{\prime}\right) \wedge p \subseteq q^{\prime} \cdot[ \\
{\left.\left.\left[\forall w^{\prime} w\left[p \cap q^{\prime}\left(w^{\prime}\right) \wedge p \cap q(w)\right] \rightarrow w^{\prime} \leq_{q^{\prime}} w\right)\right] \wedge q\left(w_{@}\right)\right] }
\end{aligned}
$$

(Torres Bustamante 2012: 356, (21))

This analysis concurs with our proposal in defining surprise in terms of the relative ranking of the asserted proposition and one focus alternative, but it differs crucially with respect to the treatment of the modal base. Note that the propositional content of (41) is asserted, hence it is part of the speaker's beliefs at the moment of utterance; thus, the backward shifting of the speaker-anchored doxastic modal base allowed by past tense plays a crucial role in avoiding the kind of "mirative paradox" that we discussed in Section 5.1 above. Since in mirative fronting there is no obligatory past tense morphology, and any past tense is interpreted as part of the propositional content, this account cannot be extended to cover mirative fronting.

\subsection{Rett \& Murray (2013)}

Rett \& Murray (2013) analyse the mirative use of the indirect evidential in Cheyenne. Their proposal is couched in Murray's (2014) framework, which distinguishes three kinds of context update that a sentence conveys: the atissue proposition, which is introduced in the context as a discourse referent; possibly a non-at-issue restriction, which is directly added to the common ground; and an illocutionary relation, like the proposal to add the at-issue proposition to the common ground. The authors characterize the ambiguity of the Cheyenne mirative evidential in terms of these distinctions: the evidential import proper is part of non-at-issue content, whereas the mirative import is part of the illocutionary relation.

Justification for this difference comes from the observation that, while the indirect evidential undergoes the "interrogative flip" in questions - that is, it becomes hearer-oriented, rather than speaker-oriented - the mirative evidential does not undergo the interrogative flip, and is in fact unavailable in questions (Rett \& Murray 2013: 461, (21)). ${ }^{38}$ Notice that in this respect our mirative fronting differs from the Cheyenne evidential, since it is available both in assertions and in yes-no questions, as illustrated in $(7) /(23)$ and in

38 Another difference that Rett \& Murray point out is that denial of the evidential import gives rise to contradiction, whereas denial of the mirative import gives rise to infelicity (see their examples (22), (27)). This, however, seems to us to relate to the epistemic vs. non-epistemic nature of the two types of import, rather than to their different relation to the speech act layer. 
Fronting and unexpectedness

(28); hence, by Rett \& Murray's criterion, mirative fronting should not be characterized as conveying an illocutionary relation. As discussed above, this mismatch is not necessarily problematic, but it may well correspond to a genuine cross-linguistic difference parallel to that observed in the domain of evidentiality.

The authors characterize the import of the Cheyenne mirative evidential as a composite illocutionary relation, simultaneously conveying (a) the proposal to add the at-issue proposition to the common ground and (b) the expression that the at-issue proposition $p$ was not part of the speaker's expectations (where the set of expectations consists of propositions that are assigned a prior probability above some standard of credence). Differently from our proposal and Torres Bustamante's, focus plays no role in defining the contextually salient set of propositions to which the at-issue proposition $p$ is related.

On the other hand, here too the speaker's expectations are not defined at the moment of utterance, but they are shifted backwards. The authors identify a recency restriction on mirativity, whereby the event of uttering a mirative sentence with at-issue content $p$ must belong in the target state of the learning event in which the speaker has learned that $p$ :

"It seems as though a speaker can utter an exclamation like Bill has a new car! at different times to different interlocutors, as long as $p$ is relevant and as long as the time of utterance is the first opportunity the speaker has to express surprise to that interlocutor that $p . "$

(Rett \& Murray 2013: 464; emphasis ours)

In the proposed analysis, the recency restriction is captured by a constraint to the effect that the at-issue proposition $p$ was not in the speaker's set of expectations $E$ at the time of the learning event at which the speaker learned that $p$. Thus, here too the speaker's expectations are shifted backwards to the time of the learning event. ${ }^{39}$

Interestingly, the recency restriction as characterized in the above quote seems to imply that for a mirative construction to be felicitous in a context,

39 See also Rett 2011: \$3.1 on exclamatives. The "recency restriction" seems to find support in the fact that mirativity is often described in terms of sudden discovery or sudden realization. However, Aikhenvald 2012: 458-462 shows that in a number of languages sudden discovery and surprise are marked differently, by means of distinct markers, and that these two values may in fact be associated or dissociated in a range of combinations. 
the at-issue proposition cannot be part of the common ground presuppositions of the participants: this corresponds to the constraint that we identified in Section 5.1 above. In this respect, we believe that our solution to the 'mirative paradox' is a possible alternative to the backward shifting of a speaker-anchored doxastic modal base (at least for cases where the prejacent proposition is not presupposed, as in Rett \& Murray's case and in our MF). As argued above, the relevant modal base for the interpretation of MF is the context set as defined by the conversational common ground prior to, and independently of, the acceptance of the clause's propositional content and its incorporation in the common ground (both in case of an assertion and of a yes-no question).

At this point it is time to conclude this digression and return to the main thread of our discussion.

\section{Partial focus fronting}

In Section 2.1 we have argued, on the basis of the prosodic evidence, that the fronted constituent in MF qualifies as a narrow focus. But previous discussions have pointed out a problem concerning the extension of focus in MF. Consider the exchange in (43):

(43) A: Eccoti qui! Cos'è successo? here you are what is happened

B: Una multa da 500 euro $\mathrm{mi}$ sono beccato! a fine of 500 euros me.cL am got

'A: Here you are at last! What happened?

B: I got a fine of 500 euros!'

The focus constituent of a sentence is standardly identified by means of the question-answer congruence criterion, whereby the focus structure of an answer is determined by the semantics of the question that it answers: in Alternative Semantics terms, this criterion requires that the set of focus alternatives of the answer be a superset of the question denotation (Rooth 1992: 85). ${ }^{40}$ On the pragmatic side, focus in an assertion presupposes that the asserted sentence be congruent to the current Question Under Discussion,

40 In Structured Meanings terms, instead, the background of the answer must be parallel to the background of the question, and the alternatives of the focus phrase in the answer must include (or be identical to) the restriction of the wh-phrase in the question (e.g., Krifka 
Fronting and unexpectedness

namely the question that sets the immediate goal of the discourse (Roberts 2012: (26)); this congruence qualifies the assertion as a relevant discourse move.

In (43), then, the general question 'What happened?' requires a broad focus answer, in which the whole clause is in focus. However, fronting targets the direct object only: thus, if the fronted constituent qualifies as the maximal focus of the sentence, question-answer congruence is not satisfied..$^{41}$ It is for this reason that structures like (43B) have been dubbed "partial focus movement” (Zimmermann 2007; see also Fanselow \& Lenertová 2010). To put it differently, the answer (43B) apparently shows the coexistence of two overlapping foci: the broad focus required by question-answer congruence, and the narrow focus on the direct object which supports the mirative implicature.

Notice that the two foci cannot be completely dissociated: a narrow focus constituent fronted by MF cannot cooccur with another constituent narrowly focussed by question-answer congruence:

(44) A: Chi ha aspettato i ragazzi a casa?
who has waited-for the boys at home
B: \# Per due ore li ha aspettati Franca! ${ }^{42}$
for two hours them.CL has waited-for Franca
Intended:
'A: Who waited for the boys at home?
B: Franca waited for them for two hours!'

This is plausibly due to the fact that the fronted adverbial in B's reply is part of the background of the answer with respect to question-answer congruence: since it is not included in the background of A's question, the congruence requirement is not satisfied.

2006: §4.3). For a detailed comparison of the two approaches, see Beaver \& Clark 2008: ch. 4 and Krifka 2011.

41 Beaver \& Clark (2008: esp. §2.7) modify Roberts’s congruence requirement in their Focus Principle, according to which some part of a declarative utterance must evoke a set of alternatives containing all the Rooth-Hamblin alternatives of the Current Question. Even under this principle, narrow focus on the fronted direct object in $(43 \mathrm{~B})$ is not sufficient to evoke alternatives corresponding to the Current Question 'What happened?'.

42 The judgment is clear-cut if the fronted adverb per due ore is realized with the intonation characterizing MF (i.e., $\mathrm{H}^{\star \mathrm{L}}$-, see Section 2.1), and the clause-final subject Franca with the nuclear pitch accent associated with narrow (information) focus, i.e., H+L* (see Bocci 2013). 
The crucial difference between (43B) and (44B) is that the former involves broad focus for question-answer congruence, and the latter involves narrow focus on two distinct constituents. We will assume, following Selkirk (2007) and Katz \& Selkirk (2011), that "broad focus" is actually not marked by an F-feature. Note in fact that, in alternative semantics terms, when the whole proposition is in focus there is no way to constrain the shape of the proposition-level alternatives. (In structured meaning terms, the background will be empty, and we would have to stipulate a contextually relevant set of alternative propositions including - or identical to - a congruent question: but this is a very counter-intuitive characterization of all-new statements.) In our view, this justifies the hypothesis that so called "broad focus" is actually not a focus at all. This in turn implies that no conflicting focus structures are involved in an all-new sentence featuring mirative fronting, like (43B) above.

\section{Concluding remarks and future prospects}

To sum up, in this paper we have proposed an analysis of the mirative import which can be associated with the fronting of a focal constituent in Italian: this conveys that the asserted proposition is less likely than one or more distinct focus alternatives (see Grosz 2011). We have characterized the mirative import as a conventional implicature but, following an insight of Zimmermann (2007), we have argued that it is not purely anchored to the speaker: it is based on a shared modal base (the context set) and on an ordering source that can be anchored to one of the conversational participants, or to the whole conversational community.

Since the interpretation of the mirative import crucially involves an ordering source (or rather, a cloud of ordering sources), we have proposed that it qualifies as an evaluative implicature. Moreover, since the mirative proposition can be accepted or rejected by the interlocutors independently from the prejacent proposition, we have proposed that it qualifies as an evaluative speaker commitment and, when accepted by the interlocutors, it becomes a joint evaluative commitment. In both respects, the mirative implicature differs from Potts's expressive meaning, which expresses a purely subjective emotional state.

A yet open question concerns the status of the implicature trigger in the structure (30), repeated here as (45):

(45) $\left.\quad{ }_{X} \mathrm{~F} \mathrm{IMP}_{C}\left[{ }_{\phi}\left[{ }_{\alpha} \mathrm{XP}_{F} \ldots t_{\alpha}\right] \sim C_{\phi}\right]_{X}\right]$ 
Fronting and unexpectedness

Not everyone would accept the hypothesis that the implicature trigger dubbed "F-IMP" corresponds to a covert element in the syntactic tree. Note however that, if the mirative import had no syntactic incarnation, the only possible trigger for the implicature would be the prosodic marking (Section 2.1). This would require the interpretation process to apply to a syntactic structure augmented with prosodic information - a not unreasonable assumption, but one that clearly departs from the usual T-model of the generative framework. In this respect, a syntactic implementation would seem to be the most conservative solution.

One possible syntactic implementation of (45) is in the cartographic framework of Rizzi $(1997,2001)$, in which the compositional layers would be identified with dedicated functional projections at the periphery of the clausal structure. In particular, the "propositional core" would correspond to Rizzi's FinP; $\alpha$, the landing site for focus fronting, would correspond to the specifier of what Rizzi dubs the Focus Phrase (but the adjoined squiggle operator requires a further "focus" layer, not contemplated in Rizzi's structured meaning approach). The implicature trigger F-IMP ${ }_{C}$ would be hosted in a functional projection above the focus-related projection(s), and the question/assertion operators would be hosted in even higher projections (cf. Rizzi's (2001) Int and Force). However, we are well aware that the choice of implementation is strongly conditioned by one's general theoretical preferences, for example a preference for maximally transparent mapping from the syntactic structure to the compositional interpretation, versus a preference for avoiding covert elements in the syntax. Therefore, we will not commit ourselves to one specific implementation.

Independently of this choice, we believe that we have identified the necessary ingredients of a satisfactory analysis of MF; we also hope that the foregoing discussion has made a clear case for the existence of evaluative implicatures, and the fact that they give rise to negotiable evaluative commitments.

\section{Appendix: The prosodic experiment}

The experimental items consisted of six pairs of sentences in which a fronting structure was presented twice: in a mirative and in a corrective context. ${ }^{43}$

43 These experimental items were part of a larger syntactic experiment aimed to test the acceptability of focus fronting in Italian under different conditions, which, in addition to mirative and corrective, also included merely contrastive focus (that is, an utterance-internal 
Out of the six pairs of sentences, three were quasi-minimal pairs: see items (1)-(3) below. In the other three pairs the target sentences differed in some relevant respects (properties of the stressed syllable, length of the postfocal material, or length of the focused constituent): see items (4)-(6) below. The non-matching pairs were designed to explore preliminarily to what extent phonological factors like the length of the fronted constituent or the length of the rest of the clause could affect the prosodic realization of the sentence in the mirative condition.

We elicited the production of the experimental items by six native speakers of Italian ( 4 women, 2 men), as read speech. ${ }^{44}$ We thus collected a corpus of 288 utterances ( 6 items $\times 2$ conditions $\times 4$ repetitions $\times 6$ subjects), out of which we randomly picked up 2 repetitions per subject for the analysis (144 utterances). We manually segmented the sentences into phonemes and we ToBI-transcribed them. We extracted several measures from the tagged corpus via Praat scripts: for the first vowel of the fronted constituent, the mean and median f0 values; for the stressed syllable and vowel of the fronted constituent, the minimum and maximum f0 values, the f0 standard deviation, and the alignment of the targets with respect to the syllable/vowel onset and their relative alignment with respect the total syllable/vowel duration. For the statistical analysis of the phonetic parameters, we took only into account the minimal pairs.

It is important to note that the negative tags in the corrective items were invariantly realized as independent intonational phrases, separated from the target clause by a strong prosodic boundary (mostly separated by actual silent pauses); this amounts to saying that the occurrence of the negative tag does not affect the relevant prosodic aspects of the target clause. As discussed in Section 2.1, our data show that the two conditions clearly contrast with respect to the pitch contour realized at the beginning of the fronted constituent (see Figure 1 and Figure 2 in Section 2.1). The pitch is high on the initial syllable of the constituent in the mirative condition, while it is low in the corrective condition. This is observed for all the items. See Figure 3 ,

contrast between the focus and an alternative conveyed in a negative tag, but without a corrective import with respect to a previous utterance). The results showed that focus fronting is not admitted in the merely contrastive condition (see Bianchi, Bocci \& Cruschina 2015).

44 The sentences were recorded in a quiet room with head-mounted microphone (Shure Beta53) at a $48 \mathrm{kHz}$ sampling rate (16-bit resolution) and then downsampled at $16 \mathrm{kHz}$ in Praat. 


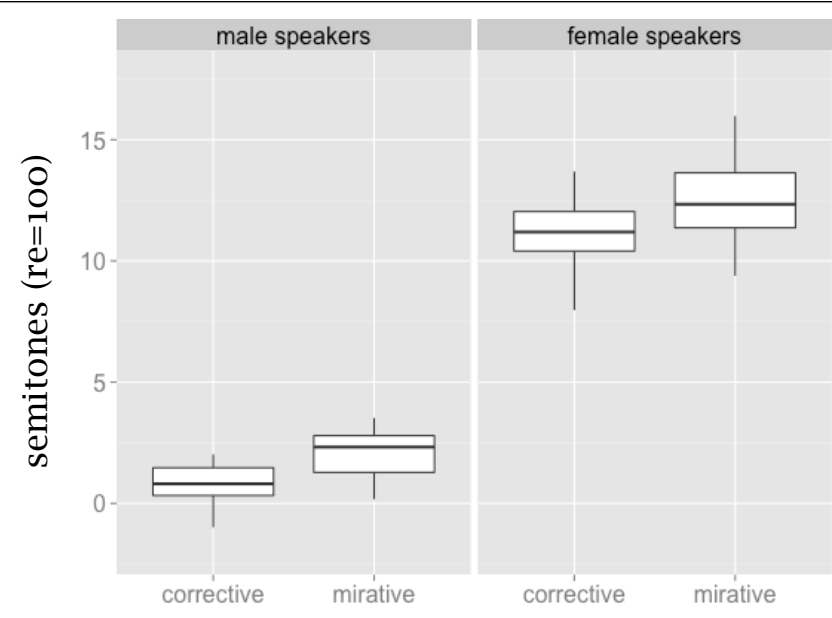

Figure 3 Box-plots of the mean fo values (in semitones, re=100) of the fronted constituent's first vowel for the mirative and the corrective condition in the minimal pairs.

which reports the mean $\mathrm{f} 0$ values of the first vowel in the two conditions for the subset of the minimal pairs.

The difference between the two conditions is confirmed by statistical analyses based on multi-level mixed effects regressions performed on the subset of the minimal pairs. We specified the mean f0 values (in semitones, $\mathrm{re}=100$ ) of the first vowel as the dependent variable and the context type (corrective vs. mirative) as a fixed effect. The maximal random structure justified by the data included random intercepts for speaker and item, as well as random slope for speaker. The test showed that the mean f0 values of the initial vowel are significantly lower in the corrective condition than in the mirative one: Estimate: -1.7 , Std. Error: $0.42, p<.001$. Analogous results are obtained for the vowel's median f0 values (Estimate: -1.7, Std. Error: 0.35, $p<.001$ ) and for the f0 values at the vowel midpoint (Estimate: -1.8 , Std. Error: $0.47, p<.01)$. We therefore conclude that in the mirative condition the left-hand boundary of the fronted constituent is tonally associates with a high boundary tone, that is, $\% \mathrm{H}$, in contrast to the corrective condition where the boundary is tonally unspecified or associates with a low boundary tone.

The second difference distinguishing the corrective and the mirative condition concerns the pitch contour realized on the stressed syllable of the rightmost word in the fronted constituent. This contrast is illustrated in Figure 4, where panel A shows how, in the corrective condition, the stressed 
A.

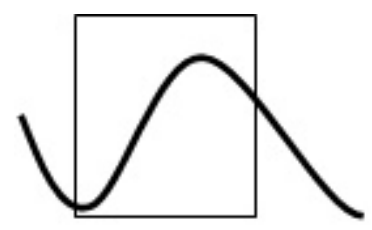

stressed syllable
B.

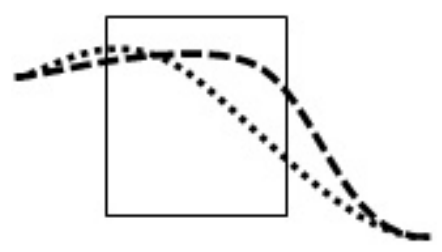

stressed syllable

Figure 4 Schemes of phonetic forms of the pitch contour observed on the stressed syllable of the rightmost word in the fronted constituent. Panel A: corrective condition; panel B: mirative condition.

syllable is typically realized with a very steep rise that starts from a low target aligned with the syllabic onset and ends in a peak occurring within the rhyme. Panel B of Figure 4, by contrast, illustrates how, in the mirative condition, there is no low target aligned with syllabic onset. The stressed syllable is rather characterized by a high target coinciding with the end of the high plateau (see also Figures 1 and 2 in Section 2.1, and the relevant discussion):

In order to corroborate this description, we compared for the minimal pairs the difference between the fo value of the high target and the fo value at the onset of the stressed syllable in the two conditions, that is, the amount of rise. We carried out a linear mixed effects analysis with context type (mirative vs. corrective) as a fixed effect. The maximal random effect structure justified by the data included random intercepts for item and random slopes and intercepts for speaker. The analysis showed that the f0 difference (in semitones, $r e=100$ ) between the stressed syllable onset's f0 value and the stressed syllable's peak is significantly higher in the corrective condition: Estimate: 3.5, Std. Error: 0.75, $p<.01$. Furthermore, we tested with a similar model the amount of pitch variation, quantified as the standard deviation of the pitch (in semitones). As expected, the standard deviation of the pitch on the stressed syllable is significantly higher in the corrective condition than in the mirative one: Estimate: 1.1, Std. Error: 0.22, $p<.001$.

In line with previous studies (see Bocci 2013 and the references therein), we analyse the rise-fall movement characterizing the last stressed syllable of the fronted constituent in the corrective condition as the result of the interpolation between the nuclear pitch accent $\mathrm{L}+\mathrm{H}^{*}$ associated with the stressed syllable and the phrase accent L- associated with the right-hand boundary of 
Fronting and unexpectedness

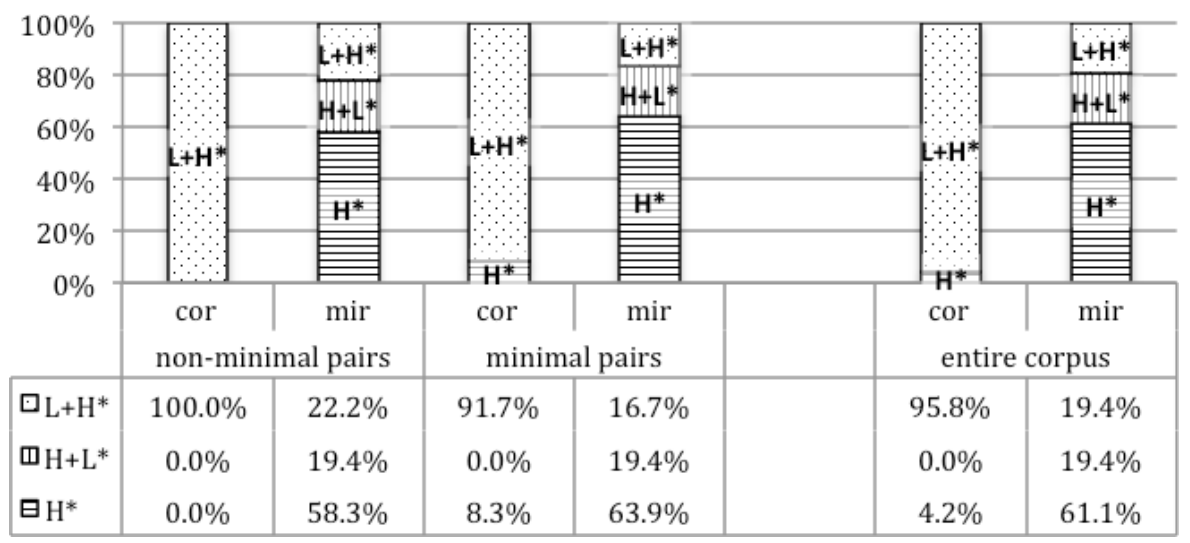

Table 1 Distribution of the nuclear pitch accents associated with the fronted constituent for the mirative and the corrective condition: in minimal and non-minimal pairs and in the entire corpus.

the constituent. The $\mathrm{L}+\mathrm{H}^{*}$ pitch accent was systematically observed in the corrective condition for all the items: out of the entire corpus, we transcribed the fronted constituent as associated with $\mathrm{L}+\mathrm{H}^{*}$ in $96 \%$ of the utterances. For the residual $4 \%$ of the cases, we failed to identify a clear leading tone aligned with the syllabic onset and we thus transcribed the pitch accent as $\mathrm{H}^{*}$. See Table 1.

As mentioned above, the high plateau that characterizes the fronted constituent in the mirative condition ends in a high target that can be aligned early or late within the stressed syllable. See Figure 4, panel B. In order to mark transparently the alignment of the high target, we decided to transcribe the pitch contour as $\mathrm{H}^{*}$ when the high target occurred within the rhyme and most of the syllable was realized with a sustained high pitch, and as $\mathrm{H}+\mathrm{L}^{*}$ when the high target occurred before the steady part of the vowel and most part of the syllable was realized as a fall. Out of the entire corpus, $61 \%$ of the utterances in the mirative condition were transcribed as $\mathrm{H}^{*}$ and $19 \%$ as $\mathrm{H}+\mathrm{L}^{*}$. See Table 1. Although the alternation between $\mathrm{H}+\mathrm{L}^{*}$ and $\mathrm{H}^{*}$ does not seem to be phonologically conditioned in our corpus, at the present stage, we do not exclude that the early alignment of the high target (transcribed as $\mathrm{H}+\mathrm{L}^{*}$ ) is to be reinterpreted as a phonetic variant of $\mathrm{H}^{*}$. Crucially, the cases transcribed as $\mathrm{H}^{*}$ and the ones transcribed as $\mathrm{H}+\mathrm{L}^{*}$ share an important aspect: in both cases, the fronted constituent is systematically realized with the initial high boundary tone $\% \mathrm{H}$. 
Finally, out of the entire set of mirative items, in 19\% of the cases the fronted constituent was realized with the pattern observed for the corrective condition: the \%H at the left-hand of the fronted constituent does not occur and the final stressed syllable is realized with a rise-fall contour, that is, $\mathrm{L}+\mathrm{H}^{*}$ L-. These findings are observed in both minimal pairs and the non-minimal pairs. We assume that these residual mirative cases in which the fronted constituent was realized with the "corrective" tune $\mathrm{L}+\mathrm{H}^{*}-\mathrm{L}$ are due to a noise effect: the speakers probably failed to correctly identify the intended interpretation.

To ascertain whether the distribution of the nuclear pitch accents associated with the fronted constituent is predicted by the context (mirative vs. corrective), results from the entire corpus were tested by means of a multi-level mixed effects regression with log odds of the occurrence of $\mathrm{L}+\mathrm{H}^{*}$ against alternative outcomes (i.e., $\mathrm{H}+\mathrm{L}^{*}$ and $\mathrm{H}^{*}$ altogether) as the dependent variable, context (mirative vs. corrective) and type of subcorpus (minimal pairs vs. non minimal pairs) as the fixed effects and by-subject random intercepts and slopes. The analysis revealed that the probability of observing $\mathrm{L}+\mathrm{H}^{*}$ is significantly lower in the mirative condition: Estimate: -3.8, Std. Error: $0.42, p<.001$. Notably, the type of subcorpus does not affect the pitch accent selection, nor does the interaction between type of context and type of subcorpus, confirming that the observed PA-distribution in the minimal pairs does not differ from the one observed in non-minimal pairs (see Table 1).

On the basis of our results, we propose that the tunes associated with the fronted constituent in the mirative condition are $\% \mathrm{H} \mathrm{H}^{*} \mathrm{~L}-$ and $\% \mathrm{H} \mathrm{H}+\mathrm{L}^{*} \mathrm{~L}-$. By contrast, the tune associated with the corrective import is $\mathrm{L}+\mathrm{H}^{*} \mathrm{~L}-($ as already found in previous research; see, a.o., Bocci 2013). Accordingly, the mirative and corrective import contrast intonationally in two distinct respects:

i. the occurrence of a \% boundary tone;

ii. the selection of the nuclear pitch accent (see Table 1).

\section{Experimental stimuli}

\section{(1a) Mirative}

[Claudia descrive a Bruno i regali che ha ricevuto per la laurea.] 'Claudia gives Bruno a description of the presents she got for her graduation.' 
Fronting and unexpectedness

C: Una collana di corniole mi hanno regalato! Chi se l' a necklace of carnelian me have given who REFL it aspettava un regalo così costoso? expected a present so expensive

'They gave me a carnelian necklace! Who would have expected such an expensive present?'

(1b) Corrective

[Claudia e Bruno parlano dei regali che Maria ha ricevuto per la sua laurea.]

'Claudia and Bruno talk about the presents Maria got for her graduation.'

C: I suoi genitori le hanno regalato un anello.

the her parents her have given a ring

'Her parents gave her a ring.'

B: Guarda che ti sbagli! Una collana di corniole le hanno look that you are-wrong a necklace of carnelian her have regalato! Non un anello! given not a ring

'You are wrong! They gave her a carnelian necklace! Not a ring!'

(2a) Mirative

[Carla racconta a Beatrice di Paolo e delle conseguenze di una sua nuotata al mare in pieno inverno.]

'Carla tells Beatrice about Paolo and about the consequences of his swimming in the sea in midwinter.'

C: Pensa un po'... Una polmonite si è preso! Però se l'è think a little a pneumonia REFL is taken but REFL it is cercata! sought

'Guess what! He caught pneumonia! But he asked for it!' 
(2b) Corrective

[Lea e Marta parlano di Paolo e della sua assenza dal lavoro per malattia.]

'Lea and Marta talk about Paolo and about his absence at work due to illness.'

L: Pensa un po'... Paolo si è preso una polmonite.

think a little Paolo REFL is taken a pneumonia

'Guess what... Paolo caught pneumonia.'

M: Guarda che ti sbagli! Mi ha chiamato ieri... Una look that you are-wrong me has called yesterday a tonsillite si è preso! Non una polmonite!

tonsillitis REFL is taken not a pneumonia

'You are wrong! He called me yesterday... He came down with tonsillitis! Not pneumonia!'

(3a) Mirative

[Anna e Beatrice parlano di Lea e Gianni che si sono appena sposati.] 'Anna and Beatrice talk about Lea and Gianni, who just got married.'

A: $\mathrm{E}$ io che pensavo che non avessero nemmeno un soldo! and I that thought that not have.SBJV.3PL even a cent Indovina un po'?! Alle Maldive sono andati in viaggio di guess a little to-the Maldives are gone in journey of nozze!

wedding

'I thought that they were completely penniless! Guess what?! They went to the Maldives on honeymoon.'

(3b) Corrective

[Anna e Beatrice parlano di Lea e Gianni che si sono appena sposati.] 'Anna and Beatrice talk about Lea and Gianni, who just got married.'

A: Se ho capito bene, sono andati alle isole Vergini. if have understood well, are gone to-the islands Virgin 'If I understood correctly, they went to the Virgin Islands.' 
Fronting and unexpectedness

$\mathrm{B}:$ Ti sbagli! Alle Maldive sono andati in viaggio di you are-wrong to-the Maldives are gone in journey of nozze! Non alle isole Vergini. Me l'ha detto il wedding not to-the islands Virgin me it has said the fratello di Gianni. brother of Gianni

'You are wrong! They went to the Maldives on honeymoon! Not to the Virgin Islands. Gianni's brother told me.'

(4a) Mirative

[Anna racconta a Lisa del nuovo fidanzamento del loro amico Gianni.] 'Anna tells Lisa about their friend Gianni's new engagement.'

A: Pensa te... anche questa poi... Con quell'oca di Mariangela think you also this then with that goose of Mariangela si è messo! Deve aver perso la testa... REFL is put must have lost the head

'You wouldn't believe this one too... He's dating that silly goose, Mariangela! He must have lost his mind!'

(4b) Corrective

[Anna racconta a Lisa del nuovo fidanzamento del loro amico Gianni.] 'Anna tells Lisa about their friend Gianni's new engagement.'

A: Credo che Gianni si sia messo con Giulia. believe that Gianni REFL is put with Giulia

'I believe that Gianni is dating Giulia.'

L: No ti sbagli! Con Mariangela si è messo! Non con no you are-wrong with Mariangela REFL is put not with Giulia.

Giulia

'You are wrong! He’s dating Mariangela! Not Giulia!' 
(5a) Mirative

[Pietro non è contento di una decisione dei genitori e si lamenta con la sorella.]

'Pietro is not happy with his parents' decision and complains about it to his sister.'

P: Ma porca miseria! Marina hanno invitato stasera a cena! Lo but damn it Marina have invited tonight to dinner it sanno benissimo che io non la sopporto!! know very-well that I not her stand

'Damn it! They invited Marina tonight for dinner! They do know that I can't stand her!'

(5b) Corrective

[I genitori di Pietro hanno invitato degli amici a cena. Pietro ne parla con la sorella.]

'Pietro's parents invited some friends for dinner. Pietro talks about it with his sister.'

P: Se ho capito bene ci sarà anche Giovanna. if have understood well there will-be also Giovanna

'If I understood correctly, Giovanna will also be there.'

A: No ti sbagli! Marina hanno invitato! Non Giovanna! no you are-wrong Marina have invited not Giovanna

'No, you are wrong! They invited Marina! Not Giovanna!'

(6a) Mirative

[Durante un quiz televisivo, un concorrente non riesce a rispondere alla domanda. Commento di un telespettatore a casa:]

'During a quiz show, a contestant is not able to answer a question. A television watcher comments at home:'

A: Ma dai, lo sanno tutti!! Michelangelo l'ha scolpita, but give it know.3PL everyone Michelangelo it has sculptured la Pietà!!

the Pietà

'Come on, everybody knows it! Michelangelo sculptured the Pietà!!' 
Fronting and unexpectedness

(6b) Corrective

[Dopo un compito in classe di educazione artistica, Andrea discute con il professore.]

'After an Art class test, Andrea talks with the teacher.'

A: A proposito della domanda sul Discobolo, io ho

to respect of-the question on-the Discobolus, I have risposto Lisippo.

answered Lysippos

'To the question on the Discobulus, I gave Lysippos as an answer.'

B: No, è sbagliato! Mirone l'ha scolpito! Non Lisippo.

no is wrong Myron it has sculptured not Lysippos

'No, that's wrong! Myron sculptured it! Not Lysippos!'

\section{References}

Abeillé, Anne, Danièle Godard \& Frédéric Sabio. 2008. Two types of preposed NP in French. In Head-Driven Phrase Structure Grammar (HPSG) conference 15, 306-324. Keihanna, Japan: CSLI on-line Publications. https: //halshs.archives-ouvertes.fr/halshs-00751057.

Aikhenvald, Alexandra Y. 2004. Evidentiality. Oxford \& New York: Oxford University Press.

Aikhenvald, Alexandra Y. 2012. The essence of mirativity. Linguistic Typology 16(3). 435-485. http://dx.doi.org/10.1515/lity-2012-0017.

Ambar, Manuela. 1999. Aspects of the syntax of focus in Portuguese. In Georges Rebuschi \& Laurice Tuller (eds.), The grammar of focus, vol. 24 (Linguistics Today), 23-54. Amsterdam: John Benjamins Publishing. http: //dx.doi.org/10.1075/la.24.02amb.

Asher, Nicholas. 2004. Discourse semantics and the focus/background distinction. In Hans Kamp \& Barbara H. Partee (eds.), Context-dependence in the analysis of linguistic meaning, 29-6o. Amsterdam: Elsevier.

Beaver, David \& Brady Clark. 2008. Sense and sensitivity: How focus determines meaning. Chichester \& Oxford: Wiley-Blackwell.

Bianchi, Valentina \& Giuliano Bocci. 2012. Should I stay or should I go? Optional focus movement in Italian. In Empirical issues in syntax and semantics 9. http://www.cssp.cnrs.fr/eiss9/eiss9_bianchi-and-bocci.pdf. 
Bianchi, Valentina, Giuliano Bocci \& Silvio Cruschina. 2015. Focus fronting and its implicatures. In Enoch O. Aboh, Jeannette C. Schaeffer \& Petra Sleeman (eds.), Romance languages and linguistic theory 2013: Selected papers from 'Going Romance’ Amsterdam 2013, 1-20. Amsterdam: John Benjamins Publishing. http://dx.doi.org/10.1075/rllt.8.o1bia.

Bocci, Giuliano. 2013. The syntax-prosody interface: A cartographic perspective with evidence from Italian. Vol. 204 (Linguistics Today). Amsterdam: John Benjamins Publishing. http://dx.doi.org/10.1075/la.204.

Chierchia, Gennaro. 2006. Broaden your views: implicatures of domain widening and the "logicality" of language. Linguistic Inquiry 37(4). 535-590. http: //dx.doi.org/10.1162/ling.2006.37.4.535.

Cruschina, Silvio. 2012. Discourse-related features and functional projections. Oxford \& New York: Oxford University Press.

DeLancey, Scott. 1997. Mirativity: the grammatical marking of unexpected information. Linguistic Typology 1(1). 33-52. http://dx.doi.org/10.1515/ lity.1997.1.1.33.

DeLancey, Scott. 2001. The mirative and evidentiality. Journal of Pragmatics 33(3). 369-382. http://dx.doi.org/10.1016/so378-2166(o1)80001-1.

Dendale, Patrick \& Liliane Tasmowski. 2001. Introduction: evidentiality and related notions. Journal of Pragmatics 33(3). 339-348. http://dx.doi.org/ 10.1016/s0378-2166(oo)oooo5-9.

Faller, Martina. 2002. Semantics and pragmatics of evidentials in Cuzco Quechua. CA: Stanford University dissertation.

Faller, Martina. 2007. Evidentiality below and above speech acts. Manuscript. http:/ / semanticsarchive . net / Archive / GZiZjBhO / Faller - evidentiality . above.below.pdf.

Fanselow, Gisbert \& Denisa Lenertová. 2010. Left peripheral focus: mismatches between syntax and information structure. Natural Language \& Linguistic Theory 29(1). 169-209. http://dx.doi.org/10.1007/s11049-0109109-X.

Farkas, Donka F. \& Kim B. Bruce. 2009. On reacting to assertions and polar questions. Journal of Semantics 27(1). 81-118. http://dx.doi.org/10.1093/ jos/ffpoio.

von Fintel, Kai \& Anthony S. Gillies. 2011. 'Might' made right. In Andy Egan \& Brian Weatherson (eds.), Epistemic modality, 108-130. Oxford: Oxford University Press. 
Fronting and unexpectedness

Frey, Werner. 2010. Ā-movement and conventional implicatures: About the grammatical encoding of emphasis in German. Lingua 120(6). 1416-1435. http://dx.doi.org/10.1016/j.lingua.2008.09.016.

Ginzburg, Jonathan. 2012. The interactive stance. New York \& Oxford: Oxford University Press.

Giurgea, Ion. 2014. Focus fronting as an exclamative marker. Paper presented at the 4oth Incontro di Grammatica Generativa, University of Trento, 13-15 February 2014.

Grosz, Patrick. 2011. On the grammar of optative constructions. Published by John Benjamins, Amsterdam-Philadelphia, 2012. Cambridge, MA: MIT dissertation. http://dx.doi.org/10.1075/la.193.

Gunlogson, Christine. 2003. True to form: Rising and falling declaratives as questions in English. New York: Routledge. http://hdl.handle.net/1802/231.

Hartmann, Katharina \& Malte Zimmermann. 2007. In place - out of place? Focus in Hausa. In Kerstin Schwabe \& Susanne Winkler (eds.), On information structure, meaning and form: Generalizations across languages, vol. 100 (Linguistics Today), 365-403. Amsterdam: John Benjamins Publishing. http://dx.doi.org/10.1075/la.100.2ohar.

Katz, Jonah \& Elisabeth Selkirk. 2011. Contrastive focus vs. discourse-new: Evidence from phonetic prominence in English. Language 87(4). 771-816. http://dx.doi.org/10.1353/lan.2011.0076.

König, Christa. 2013. Source of information and unexpected information in !Xun - evidential, mirative and counterexpectation markers. In Alexandra Y. Aikhenvald \& Anne Storch (eds.), Perception and cognition in language and culture, 69-94. Leiden: Brill.

Kratzer, Angelika. 1991. Modality. In Arnim von Stechow \& Dieter Wunderlich (eds.), Semantics: An international handbook of contemporary research, 639-650. Berlin: Mouton de Gruyter.

Kratzer, Angelika. 2012. Modals and conditionals. New and revised perspectives. New York \& Oxford: Oxford University Press.

Krifka, Manfred. 2006. Association with focus phrases. In Valeria Molnár \& Susanne Winkler (eds.), The architecture of focus, 105-136. Berlin \& New York: Mouton de Gruyter.

Krifka, Manfred. 2011. Questions. In Klaus von Heusinger, Claudia Maienborn \& Paul Portner (eds.), Semantics. An international handbook of natural language meaning, vol. 2, 1742-1758. Berlin: Mouton de Gruyter. 
Lasersohn, Peter. 2005. Context dependence, disagreement, and predicates of personal taste. Linguistics and Philosophy 28(6). 643-686. http://dx.doi. org/10.1007/s10988-005-0596-x.

Lazard, Gilbert. 1999. Mirativity, evidentiality, mediativity, or other? Linguistic Typology 3(1). 91-110. http://dx.doi.org/10.1515/lity.1999.3.1.91.

Lazard, Gilbert. 2001. On the grammaticalization of evidentiality. Journal of Pragmatics 33(3). 359-367. http://dx.doi.org/10.1016/so378-2166(oo) oooo8-4.

van Leusen, Noor. 2004. Incompatibility in context: A diagnosis of correction. Journal of Semantics 21(4). 415-441. http://dx.doi.org/10.1093/jos/21.4. 415.

Matthewson, Lisa, Hotze Rullmann \& Henry Davis. 2008. Evidentials as epistemic modals: Evidence from St'át'imcets. In Jeroen van Craenenbroeck (ed.), Linguistic variation yearbook 2007, vol. 7, 201-254. Amsterdam: John Benjamins Publishing. http://dx.doi.org/10.1075/livy.7.o7mat.

Moltmann, Friederike. 2009. Relative truth and the first person. Philosophical Studies 150(2). 187-220. http://dx.doi.org/10.1007/s11098-009-9383-9.

Murray, Sarah E. 2010. Evidentiality and the structure of speech acts. New Brunswick, NJ: Rutgers University dissertation.

Murray, Sarah E. 2014. Varieties of update. Semantics and Pragmatics 7(2). 1-53. http://dx.doi.org/10.3765/sp.7.2.

Partee, Barbara H. 1995. Lexical semantics and compositionality. In Lila Gleitman, Mark Liberman \& Daniel N. Osherson (eds.), An invitation to cognitive science. Part I: Language, 311-36o. Cambridge, MA: MIT Press.

Pearson, Hazel. 2012. A judge-free semantics for predicates of personal taste. Journal of Semantics 30(1). 103-154. http://dx.doi.org/10.1093/jos/ffsoo1.

Peterson, Tyler. 2010. Examining the mirative and nonliteral uses of evidentials. In Tyler Peterson \& Uli Sauerland (eds.), Evidence from evidentials, vol. 28 (University of British Columbia Working Papers in Linguistics (UBCWPL)), 129-159. Vancouver, BC: UBC Department of Linguistics.

Peterson, Tyler. 2012. Evidentiality and the unprepared mind. http:// semanticsarchive.net/Archive/jg1NDNkO/mirativity2.pdf.

Plungian, Vladimir A. 2001. The place of evidentiality within the universal grammatical space. Journal of Pragmatics 33(3). 349-357. http://dx.doi. org/10.1016/so378-2166(oo)oooo6-o.

Potts, Christopher. 2007a. Conventional implicatures, a distinguished class of meanings. In Gillian Ramchand \& Charles Reiss (eds.), The Oxford 
Fronting and unexpectedness

handbook of linguistic interfaces (Studies in Theoretical Linguistics), 475501. Oxford: Oxford University Press.

Potts, Christopher. 2007b. The expressive dimension. Theoretical Linguistics 33(2). 165-198. http://dx.doi.org/10.1515/tl.2007.011.

Potts, Christopher. 2012. Conventional implicature and expressive content. In Claudia Maienborn, Klaus von Heusinger \& Paul Portner (eds.), Semantics: An international handbook of natural language meaning, vol. 3, 2516-2536. This article was written in 2008. Berlin: Mouton de Gruyter.

Rett, Jessica. 2011. Exclamatives, degrees and speech acts. Linguistics and Philosophy 34(5). 411-442. http://dx.doi.org/10.1007/s10988-011-9103-8.

Rett, Jessica \& Sarah E. Murray. 2013. A semantic account of mirative evidentials. In Semantics and Linguistic Theory (SALT) 23, 453-472. http: //dx.doi.org/10.3765/salt.v23io.2687.

Rizzi, Luigi. 1997. The fine structure of the left periphery. In Liliane Haegeman (ed.), Elements of grammar: Handbook in generative syntax, 281-337. Dordrecht: Springer Netherlands. http://dx.doi.org/10.1007/978-94-0115420-8_7.

Rizzi, Luigi. 2001. On the position "int(errogative)" in the left periphery of the clause. In Guglielmo Cinque \& Giampaolo Salvi (eds.), Current studies in Italian syntax: Essays offered to Lorenzo Renzi, 267-296. Amsterdam: Elsevier.

Roberts, Craige. 2012. Information structure in discourse: towards an integrated formal theory of pragmatics. Semantics and Pragmatics 5. 1-69. http://dx.doi.org/10.3765/sp.5.6.

Rooth, Mats. 1992. A theory of focus interpretation. Natural Language Semantics 1(1). 75-116. http://dx.doi.org/10.1007/bfo2342617.

Selkirk, Elisabeth. 2007. Contrastive focus, givenness and unmarked status of "discourse new". In Caroline Féry, Gisbert Fanselow \& Manfred Krifka (eds.), The notions of information structure, vol. 6 (Working Papers of the Sonderforschungsbereich (SFB) 632), 125-146. Potsdam: Universitätsverlag Potsdam.

Squartini, Mario. 2008. Lexical vs. grammatical evidentiality in French and Italian. Linguistics 46(5). 917-947. http://dx.doi.org/10.1515/ling.2008.030. Squartini, Mario. 2010. Where mood, modality and illocution meet: the morphosyntax of Romance conjectures. In Martin Becker \& Eva-Maria Remberger (eds.), Modality and mood in romance, modal interpretation, mood selection, and mood alternation, 109-132. Tübingen: Niemeyer. http://dx. doi.org/10.1515/9783110234343.1.109. 
Stalnaker, Robert. 1978. Assertion. In Peter Cole (ed.), Syntax and semantics 9: Pragmatics, 315-332. New York: Academic Press.

Stalnaker, Robert. 1984. Inquiry. Cambridge, MA: MIT Press.

Stephenson, Tamina. 2007. Judge dependence, epistemic modals, and predicates of personal taste. Linguistics and Philosophy 30(4). 487-525. http: //dx.doi.org/10.1007/s10988-008-9023-4.

Torres Bustamante, Teresa. 2012. Real tense and real aspect in mirativity. In Semantics and Linguistic Theory (SALT) 22, 347-364. http://dx.doi.org/10. 3765/salt.v22io.2650.

Torres Bustamante, Teresa. 2013. On the syntax and semantics of mirativity: Evidence from Spanish and Albanian. New Brunswick, NJ: Rutgers University dissertation.

Villalta, Elisabeth. 2007. Context dependence in the interpretation of questions and subjunctives. Universität Tübingen dissertation.

Zanuttini, Raffaella \& Paul Portner. 2003. Exclamative clauses: At the syntaxsemantics interface. Language 79(1). 39-81. http://dx.doi.org/10.1353/lan. 2003.0105.

Zimmermann, Malte. 2007. Contrastive focus. In Caroline Féry, Gisbert Fanselow \& Manfred Krifka (eds.), The notions of information structure, vol. 6 (Working Papers of the Sonderforschungsbereich (SFB) 632), 147-159. Potsdam: Universitätsverlag Potsdam.

Valentina Bianchi

Department of Social, Political and Cognitive Sciences

University of Siena, Italy

valentina.bianchi@unisi.it

Silvio Cruschina

Institut für Romanistik

University of Vienna, Austria

silvio.cruschina@univie.ac.at
Giuliano Bocci

Département de Linguistique

University of Geneva, Switzerland

giuliano.bocci@unige.ch 